\title{
Antimicrobianos en neonatología. Parte I: Recomendaciones de dosificaciones basadas, en la más reciente evidencia en recién nacidos Comité Consultivo de Infecciones Neonatales, Sociedad Chilena de Infectología
}

\author{
Antibiotics in neonatology. Part I: Dosage recommendations based on the most recent evidence in newborns \\ Advisory Committee on Neonatal Infections, Chilean Society of Infectious Diseases
}

Alejandra Sandoval C. 1,2, Marta Aravena U. ${ }^{1}$, Fernanda Cofré S. ${ }^{1,3}$, Luis Delpiano M. ${ }^{1,4}$, Rubén Hernández M. ${ }^{4,5}$, Mariluz Hernández E. 1,6, Giannina Izquierdo C.1,7, Yenis Labraña C.,8 y Alejandra Reyes J.1,9

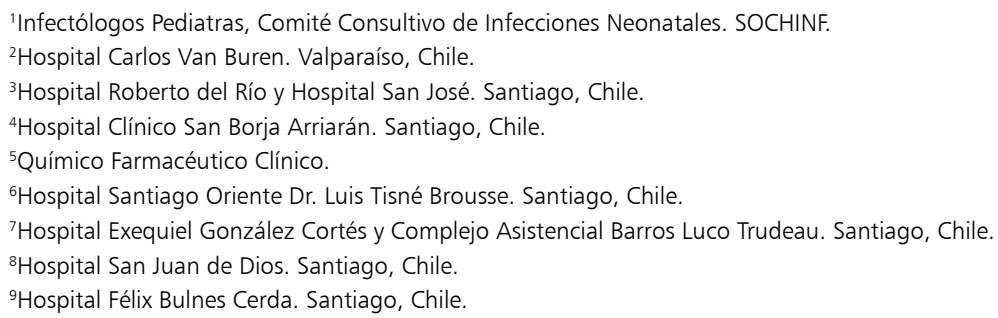

Los autores declaran no tener conflicto de interés.

Este manuscrito no posee fuentes de financiamiento.

Recibido: 27 de julio de 2020 / Aceptado: 26 de agosto de 2020

\section{Resumen}

Los antimicrobianos son los medicamentos más utilizados en los neonatos durante su primer mes de vida cuando se encuentran en unidades neonatales, principalmente por el alto riesgo que presentan de adquirir infecciones graves como la sepsis. La mayoría de estos antimicrobianos se utilizan con dosis extrapoladas en base a las recomendaciones en población adulta y niños mayores, a pesar de que la fisiopatología en los recién nacidos es absolutamente diferente. Lo anterior lleva a un mayor riesgo a que ocurran más efectos adversos los que pueden conducir a una mayor toxicidad y a fallas terapéuticas, entre otros. En la última década se han realizado mayores estudios farmacocinéticos de antimicrobianos en neonatos; esta reciente evidencia ha permitido nuevas recomendaciones de dosificación considerando el peso y la edad gestacional del recién nacido, entre otras variables, de acuerdo al antimicrobiano estudiado. En base a una mayor evidencia sobre el comportamiento farmacocinético de los antimicrobianos en neonatos, se ha elaborado este documento para así facilitar y promover su correcto uso en las unidades neonatales.

Palabras clave: recién nacidos; antimicrobianos; farmacocinética; concentración plasmática; dosificación; vancomicina; aminoglucósidos.

\section{Abstract}

Antibiotics are the most widely used medications in neonates during their first month of life in neonatal units, mainly due to the high risk they present of acquiring serious infections such as sepsis. Most of these antibiotics are used with extrapolated doses based on the suggestions in the adult population and older children, despite the fact that the pathophysiology in newborns is absolutely different. This leads to a higher risk of more adverse effects occurring, which can lead to greater toxicity and therapeutic failures, among others. In the last decade more and more pharmacokinetic studies of antibiotics have been carried out in neonates, this recent evidence has led to new dosage recommendations taking into account the weight and gestational age of the newborn, among other variables, in agreement to the antibiotic studied. Therefore, based on the need to order and summarize the most up-to-date and most evidence-based information on antibiotics in neonates, this document was prepared to facilitate and promote its correct use in neonatal units.

Keywords: newborn; antibiotics; pharmacokinetics; plasmatic level; dosing; vancomycin; aminoglycosides.

\section{Correspondencia a:}

Alejandra Sandoval Carmona

ale7sandov@gmail.com 


\section{Introducción}

os neonatos, desde su hospitalización en una Unidad de Cuidados Intensivos Neonatales (UCIN), están expuestos a una gran variedad de medicamentos. El recién nacido $(\mathrm{RN})$, en especial el de extremo bajo peso al nacer, puede recibir hasta 17 ciclos de medicamentos, siendo $25 \%$ de ellos antimicrobianos $(\mathrm{AM})^{1}$, lo que los convierte en los fármacos más comúnmente administrados a los RN durante el primer mes de $v_{i d a}{ }^{2,3}$. La gran utilización de AM en este tipo de pacientes se debe a que presentan un alto riesgo de adquirir infecciones graves, condición favorecida por variados factores, tales como su condición de inmadurez inmunológica, una delgada barrera cutánea, la reducida respuesta humoral y la disminuida diversidad de su microbiota intestinal ${ }^{4}$.

La fisiología única de los neonatos, sumada a sus co-morbilidades y fármacos concomitantes, afectan la distribución de los AM y pueden alterar aún más su farmacocinética (FC) y farmacodinamia (FD) ${ }^{1}$. Resulta, por tanto, relevante maximizar nuestra comprensión de los perfiles FC/FD con el fin de determinar la dosificación óptima de los $\mathrm{AM}$ en neonatos ${ }^{3}$. La farmacología clínica de los RN a menudo es sustancialmente diferente a la de niños mayores y adultos, debido a que su desarrollo fisiológico depende de la edad gestacional (EG) y la edad postnatal $(\mathrm{EPN})^{1,2,5}$. Tanto la metabolización como la eliminación de los AM están influidas por el tamaño corporal y la maduración, lo que requiere ajustes de dosis a medida que los neonatos crecen ${ }^{1}$, como ocurre con la capacidad enzimática de la citocromo-P450, que sólo alcanza actividad similar al adulto a partir del año de vida ${ }^{2}$.

La dosificación de los AM depende, además, de la excreción renal y sus cambios fisiológicos durante el primer año de vida, ya que, la tasa de filtración glomerular (TFG) es extremadamente baja al nacer, en especial en los prematuros, y aumenta rápidamente después del nacimiento ${ }^{1,2,6}$. La TFG también aumenta con el incremento de EG y EPN en lactantes y generalmente se correlaciona más con la edad post-menstrual (EPM $)^{2,7}$. Además, se producen cambios profundos en la TFG y el volumen de distribución después de la primera semana de vida y estos cambios son más pronunciados cuanto más prematuro es el RN. El flujo sanguíneo renal es sólo 3\% del gasto cardíaco en el feto, pero aumenta a $10 \%$ al final de la primera semana de vida ${ }^{6,7}$. La excreción de AM a través del sistema renal también depende de la función de los túbulos renales. Los efectos de la secreción tubular están disminuidos en el RN y aumentando durante los primeros meses de vida hasta llegar a los niveles de los adultos a los 7 meses $^{2}$.

Las propiedades FC de los AM se ven afectadas, también, por factores como la barrera hemato-encefálica (BHE) inmadura que permite a ciertos AM penetrarla más fácilmente, y el contenido de agua corporal elevado en los neonatos que provoca el aumento del volumen de distribución, sobre todo de los AM hidrosolubles².

A pesar de que en los últimos 10 años se han realizado considerables esfuerzos para mejorar datos clínicos y farmacológicos de los $\mathrm{AM}$ en la población de $\mathrm{RN}^{2}$, en la mayoría de los casos todavía se indican "fuera de etiqueta" (en inglés off label), lo que significa que carecen de datos de dosificación, seguridad o eficacia descritos en los protocolos de la Food and Drug Administration (FDA) de E.U.A. ${ }^{2,3}$. A menudo, las recomendaciones de dosificación de AM para adultos, se extrapolan a niños y lactantes, ya que no existe suficiente literatura científica confiable para esta población de pacientes ${ }^{8} \mathrm{y}$, a pesar del aumento de nuevas metodologías para realizar ensayos farmacológicos y de FC/FD en neonatos ${ }^{1}$, se requieren estudios prospectivos in vivo para validar el índice FC/FD asociado con la eficacia en la población neonatal ${ }^{9}$. Todo lo anterior, puede llevar a una sub o sobre-dosificación de AM y ambas situaciones pueden ocasionar efectos adversos como resistencia antimicrobiana, toxicidad en algunos parénquimas y falla en el tratamiento ${ }^{3}$.

Con todas estas consideraciones, y con un propósito de mejorar la práctica clínica, estimamos de suma relevancia actualizar conceptos y dosificaciones de AM frecuentemente usados en la población de pacientes neonatos. El objetivo de esta revisión es dar una recomendación fundamentada de dosificación de los AM en neonatología en los que existe evidencia actualizada.

Para comenzar con la introducción a este tema es fundamental tener presentes algunas definiciones.

- Farmacocinética: procesos que experimenta un fármaco en su paso por el organismo.

- Farmacodinamia: mecanismos de acción de los fármacos, en el caso de los AM tiene que ver con su habilidad bacteriostática y bactericida.

- Concentración inhibitoria mínima (CIM): se refiere a la concentración mínima del antimicrobiano que inhibe el crecimiento bacteriano.

- Área bajo la curva de la concentración plasmática (AUC es su sigla en inglés): corresponde a la concentración de un fármaco en el plasma en un intervalo de tiempo definido, la cantidad total del fármaco que alcanza la circulación sistémica.

- $\beta$-lactamasas de espectro extendido (BLEE): resistencia a $\beta$-lactámicos hasta las cefalosporinas de tercera generación.

\section{$\beta$-lactámicos}

\section{Ampicilina}

Es un $\beta$-lactámico activo contra Streptococcus agalactiae, Listeria monocytogenes y algunos aislados de Escherichia coli, agentes frecuentes de infección en el 
$\mathrm{RN}^{2}$. Como todos los integrantes de esta familia de AM, su objetivo FD (el más correlacionado con la actividad bactericida máxima), es el tiempo que permanecen las concentraciones plasmáticas $(\mathrm{CP})$ sobre la CIM $(\mathrm{T}>\mathrm{CIM})^{1,6}$. La vida media sérica de ampicilina disminuye rápidamente en las primeras dos semanas de vida, como resultado del aumento de la depuración del fármaco ${ }^{6}$. A pesar de ser el $\beta$-lactámico más comúnmente administrado en UCIN, existen escasos datos sobre su dosificación en neonatos ${ }^{1,2,6}$, los que se basan actualmente en la EG y la EPM ${ }^{1,6}$.

Hasta hace poco, las recomendaciones de dosificación eran principalmente el resultado de la extrapolación de estudios en adultos y niños mayores ${ }^{1}$. En comparación con los regímenes recomendados en las referencias pediátricas, una de las más recientes estrategias de dosificación propuestas explica el cambio en la función renal durante las primeras semanas de vida y permite su administración con menor frecuencia ${ }^{6}$.

Ampicilina es hidrosoluble y su aclaramiento se determina fundamentalmente por filtración glomerular y secreción tubular renal. Ha de considerarse que, a pesar de ser relativamente segura, tiene el potencial de efectos adversos serios como nefritis intersticial, neurotoxicidad $y$ alteración en el funcionamiento plaquetario ${ }^{2}$.

Existen sospechas de que, en los pacientes que sufren de encefalopatía hipóxico-isquémica (falla renal aguda,

\section{Tabla 1. Recomendación para la dosificación de ampicilina}

\begin{tabular}{|c|c|c|c|c|}
\hline $\begin{array}{l}\text { Tipo de } \\
\text { enfermedad }\end{array}$ & $\begin{array}{c}\text { Edad } \\
\text { gestacional } \\
\text { (semanas) }\end{array}$ & $\begin{array}{c}\text { Edad } \\
\text { postnatal } \\
\text { (días) }\end{array}$ & $\begin{array}{c}\text { Dosis de } \\
\text { mantención } \\
\text { (mg/kg/dosis) }\end{array}$ & $\begin{array}{l}\text { Intervalo de } \\
\text { las dosis } \\
\text { (h) }\end{array}$ \\
\hline \multirow[t]{3}{*}{ Bacteriemia } & $\leq 34$ & $<7$ & 50 & 12 \\
\hline & & $\geq 8 y \leq 28$ & 75 & 12 \\
\hline & $>34$ & - & 50 & 8 \\
\hline \multirow[t]{4}{*}{ Meningitis } & $\leq 34$ & $<7$ & 100 & 8 \\
\hline & & $\geq 8 y \leq 28$ & 75 & 6 \\
\hline & $>34$ & $<7$ & 100 & 8 \\
\hline & & $\geq 8 y \leq 28$ & 75 & 6 \\
\hline
\end{tabular}

Tremoulet A, Le J, Poindexter B y cols. ${ }^{6}$, Puopolo KM, Lynfield R y cols. ${ }^{11}$

Tabla 2. Recomendación para la dosificación de cloxacilina

\begin{tabular}{ccccc}
\hline $\begin{array}{c}\text { Edad gestacional } \\
\text { (semanas) }\end{array}$ & $\begin{array}{c}\text { Edad postnatal } \\
\text { (días) }\end{array}$ & $\begin{array}{c}\text { Peso } \\
\mathbf{( k g )}\end{array}$ & $\begin{array}{c}\text { Dosis } \\
(\mathbf{m g} / \mathbf{k g} / \mathbf{d o s i s})\end{array}$ & $\begin{array}{c}\text { Intervalo de } \\
\text { las dosis (h) }\end{array}$ \\
Todas & $\leq 7$ & $\leq 2$ & 25 & 12 \\
& $\leq 7$ & $>2$ & 25 & 8 \\
& $8-28$ & $\leq 2$ & 25 & 8 \\
\hline $8-28$ & $>2$ & 25 & 6 \\
\hline
\end{tabular}

http://www.Ihsc.on.ca/nicu/cloxacillin ${ }^{12}$ elevación de transaminasas y coagulopatía $)^{10}$, debieran tener dosificaciones especiales; sin embargo, aún no existen directrices claras de cómo se debieran modificar las dosis en estos casos.

La vida media de eliminación disminuye después de la primera semana de vida desde 3 a 5 h ( $\leq 7$ días) hasta 2 a 4 h (8-28 días); las dosis variarán de acuerdo a este parámetro. Con los datos $\mathrm{FC}$ recopilados, el régimen posológico neonatal recomendado alcanzó el objetivo terapéutico en $>97 \%$ de los $\mathrm{RN}$, en comparación con las recomendaciones de dosificación anteriores que alcanzaron este objetivo en $>90 \% \%^{6}$. Cabe destacar, que las simulaciones de Monte Carlo del estudio principal en que se basará nuestra recomendación, no tuvieron en cuenta la penetración de ampicilina en el líquido cefalorraquídeo (LCR), que previamente se ha informado en un rango de 11 a $65 \%$ basado en dosis de $120-200 \mathrm{mg} / \mathrm{kg} /$ día en neonatos bajo un mes de vida, con meningitis. Se necesitan mayores estudios para explorar la dosificación óptima para el tratamiento de una meningitis bacteriana aguda (MBA), especialmente en prematuros de menos de un mes de edad ${ }^{6}$. Teniendo en cuenta estos hallazgos, se entrega un régimen de dosificación simplificado basado en EG y EPN'1 (Tabla 1).

\section{Cloxacilina}

Es una penicilina semisintética nominada antiestafilocócica por su actividad in vitro contra cocáceas grampositivas aeróbicas como Staphylococcus aureus y Staphylococcus saprophyticus. Es una ventaja su excelente concentración pleural, en líquido sinovial, líquido biliar, además de lograr concentraciones bactericidas en el sistema nervioso central (SNC). Su metabolización ocurre en el hígado y se excreta por vía renal. En general, es un AM bastante efectivo y seguro. Su indicación principal es en infecciones de piel y tejidos blandos, bacteriemias, endocarditis y osteomielitis ocasionadas por $S$. aureus sensible a meticilina $(\mathrm{SASM})^{12,13}$

Dosificación recomendada de cloxacilina en neonatos en la Tabla 2.

\section{Cefalosporinas}

\section{Cefotaxima}

Cefalosporina de tercera generación, con actividad para cocáceas grampositivas (en especial Streptococcus spp) y bacilos gramnegativos (BGN). Carece de actividad contra BGN no fermentadores (Pseudomonas aeruginosa, Acinetobacter baumannii), L. monocytogenes, Enterococcus spp y anaerobios estrictos. Dentro de sus características FC destacan: una mínima metabolización hepática cuyo metabolito activo es la des-acetil-cefotaxima, una amplia distribución en distintos fluidos corporales (logrando 
concentraciones bactericidas en LCR y secreciones bronquiales), un aclaramiento renal variable (dependiendo del peso y EG) y una vida media en promedio de $3,6 \mathrm{~h}^{14-16}$. A pesar de todas las características mencionadas, su utilidad en neonatología es limitada, debido a que su uso en este tipo de pacientes se ha asociado con mayor mortalidad, como lo demostró el estudio realizado por Clark y cols., en el cual, los pacientes que recibieron la combinación ampicilina-cefotaxima versus ampicilina-gentamicina dentro de los primeros tres días de vida, tuvieron 1,5 más probabilidades de $\operatorname{morir}^{17}$. Así mismo, el estudio realizado por Cotten y cols., que evaluó una cohorte de 3.702 prematuros extremos, encontró un coeficiente de correlación de 0,67 entre el uso de cefalosporinas de tercera generación y candidiasis ${ }^{18}$. Pero también se mencionan otros problemas asociados como el aumento del riesgo de sepsis ${ }^{19}$, enterocolitis necrosante $(\mathrm{ECN})^{20} \mathrm{e}$ infecciones por aislados multi-resistentes ${ }^{21}$.

Debido a los riesgos mencionados, hoy en día se prefiere evitar el uso de cefotaxima en las UCIN y por ello, la recomendación actual es restringir su uso a situaciones muy específicas como son: la MBA causada por BGN sensibles a este AM y en caso de sospecha de sepsis precoz con falla renal.

Dosificación recomendada de cefotaxima en neonatos en la Tabla 3.

\section{Ceftarolina}

Ceftarolina fosamil es una pro-droga de la nueva cefalosporina: ceftarolina, que administrada por vía IV al paciente, es rápidamente hidrolizada en el plasma mediante enzimas con actividad de fosfatasas liberándose el AM. Se une a proteínas plasmáticas en 15 a $28 \%$, es excretada primeramente sin cambios por la orina y experimenta una mínima metabolización $(\sim 20 \%)$ a un metabolito biológicamente inerte (ceftarolina M1) ${ }^{21}$. Tiene un amplio espectro de cobertura para cocáceas grampositivas como $S$. aureus resistente a meticilina (SARM), S. agalactiae y Staphylococcus coagulasa negativa (SCN) y, para BGN incluyendo E. coli y Klebsiella pneumoniae (a excepción de aquellas cepas productoras de BLEE ${ }^{24}$. El parámetro FC/FD que mejor predice su mecanismo de acción bactericida es el tiempo por sobre la $\mathrm{CIM}^{21}$.

En Europa, ceftarolina está aprobada para el tratamiento de neumonía adquirida en la comunidad e infecciones complicadas de piel y tejidos blandos en pacientes $\geq 2$ meses de edad, con una extensión de su indicación recientemente aprobada para neonatos y lactantes $<$ de 2 meses en dosis de $6 \mathrm{mg} / \mathrm{kg} /$ dosis, administrada cada 8 h. En E.U.A. tiene la misma indicación que en Europa, salvo que la aprobación en neonatos incluye aquellos a partir de las 34 semanas y entre los 12 días $\mathrm{y}<2$ meses, con la misma dosis ${ }^{24}$.

El trabajo más actual y publicado recientemente, tuvo como objetivo primario verificar sus efectos adversos y la tolerancia, siendo la eficacia un objetivo secundario del estudio debido al pequeño número de pacientes y la concomitancia del uso de otros AM (ampicilina y aminoglucósido), siendo ambas situaciones factores limitantes para interpretar los resultados del estudio clínico y microbiológico ${ }^{24}$. Fue bien tolerada en $\mathrm{RN}$ entre $7 \mathrm{y}<60$ días de vida cursando con sepsis tardía, sin eventos adversos ${ }^{24}$.

Utilizando simulación mediante boostraping se obtuvo que el régimen de $6 \mathrm{mg} / \mathrm{kg} / \mathrm{dosis}$, administrada cada $8 \mathrm{~h}$, previamente establecido, era correcto para $\mathrm{RN}<2$ meses, resultando en un objetivo terapéutico de $>99 \%$ para $S$. aureus $^{24}$, de $>95 \%$ para SCN y $>90 \%$ para enterobacterias no productoras de $\mathrm{BLEE}^{24}$.

Hasta el momento, la FDA y la European Medicines Agency (EMA) consideraron suficientes los datos combinados de este estudio y uno realizado con anterioridad ${ }^{25}$ para establecer recomendaciones de dosificación para ceftarolina fosamil en lactantes $<2$ meses de edad ${ }^{24}$. Aunque no hay datos para determinar los objetivos FC/FD específicos para neonatos en diferentes edades gestacionales y cronológicas, para diversos patógenos en diferentes sitios de tejidos y, considerando que los $\mathrm{RN}$ carecen de defensas inmunes maduras, los objetivos terapéuticos deben ser más altos que en población adulta $\mathrm{y}$ en edades pediátricas ${ }^{24}$.

Dosificación recomendada de ceftarolina en neonatos en la Tabla 4.

\section{Ceftazidima/avibactam}

Ceftazidima/avibactam es una combinación de ceftazidima con un inhibidor de $\beta$-lactamasas: avibactam. Ceftazidima es una cefalosporina de tercera generación de amplio espectro con actividad anti-pseudomonas. Avibactam es un nuevo inhibidor de $\beta$-lactamasas/ no $\beta$-lactámico, que tiene la capacidad de inactivar varias $\beta$-lactamasas. Esta combinación es activa contra

\begin{tabular}{|c|c|c|c|}
\hline $\begin{array}{c}\text { Edad gestacional } \\
\text { (semanas) }\end{array}$ & $\begin{array}{l}\text { Edad postnatal } \\
\text { (días) }\end{array}$ & $\begin{array}{c}\text { Dosis de mantención } \\
\text { (mg/kg/dosis) }\end{array}$ & $\begin{array}{l}\text { Intervalo de } \\
\text { las dosis (h) }\end{array}$ \\
\hline Todas & $<7$ & 50 & 12 \\
\hline$<32$ & $\geq 7$ & 50 & 8 \\
\hline$\geq 32$ & $\geq 7$ & 50 & 6 \\
\hline $\begin{array}{l}\text { Meningitis Guía } \\
\text { IDSA } 2004\end{array}$ & $\begin{array}{l}\text { RN (hasta } 1 \text { mes) } \\
\text { Considerar en }<2\end{array}$ & \multicolumn{2}{|c|}{$\begin{array}{l}<7 \text { días } 100-150 \text { mg/kg/día en } 2 \text { o } 3 \text { dosis } \\
>7 \text { días } 150-200 \text { mg/kg/día en } 3 \text { o } 4 \text { dosis } \\
\text { kilos la dosis más baja y mayor fraccionamiento }\end{array}$} \\
\hline
\end{tabular}




\begin{tabular}{|cccc|}
\hline \multicolumn{2}{|c|}{ Tabla 4. Recomendación para la dosificación de ceftarolina } & \\
\hline $\begin{array}{c}\text { Edad gestacional } \\
\text { (semanas) }\end{array}$ & $\begin{array}{c}\text { Edad postnatal } \\
\text { (días) }\end{array}$ & $\begin{array}{c}\text { Dosis de mantención } \\
\text { ( } \mathbf{m g} / \mathbf{k g} / \text { dosis) }\end{array}$ & $\begin{array}{c}\text { Intervalo de } \\
\text { las dosis (h) }\end{array}$ \\
$\geq 34^{*}$ & $7-60$ & 6 & 8 \\
\hline *Puede considerarse la misma dosis para menor edad gestacional. Bradley JS, Stone GS y cols. ${ }^{24}$. \\
\hline
\end{tabular}

Tabla 5. Recomendación para la dosificación de ceftazidima/avibactam

$\begin{array}{cccc}\begin{array}{c}\text { Edad gestacional } \\ \text { (semanas) }\end{array} & \begin{array}{c}\text { Edad postnatal } \\ \text { (días) }\end{array} & \begin{array}{c}\text { Dosis de mantención } \\ \text { (mg/kg/dosis) }\end{array} & \begin{array}{c}\text { Intervalo de } \\ \text { las dosis (h) }\end{array} \\ \text { Todas } & \text { Todas* } & 62,5 & 8\end{array}$

*Aún en definición debido a los escasos datos y publicaciones. Iosifidis E, Chorafa E, y cols. ${ }^{26}$.

Tabla 6. Recomendación para la dosificación de piperacilina/tazobactam

Edad postmenstrual (semanas)

$<30$

$30-35$

$35-49$

15

Cohen-Wolkowiez M, Watt KM, y cols. ${ }^{8}$. incluye pacientes neonatales y prematuros, siendo utilizada ceftazidima/avibactam como terapia de rescate en bacterias resistentes a carbapenémicos ${ }^{26}$. En esta serie de casos, no hubo documentación de eventos adversos graves ni interrupción del fármaco, siendo hasta ahora seguro. Los eventos adversos más comúnmente reportados con el uso de ceftazidima/avibactam, tanto en niños como en adultos, son principalmente gastrointestinales, como diarrea, náuseas y vómitos ${ }^{26}$.

Dosificación recomendada de ceftazidima/avibactam en neonatos en la Tabla 5.

\section{Piperacilina/tazobactam}

Piperacilina es un $\beta$-lactámico semisintético derivado de ampicilina que se usa en combinación con tazobactam, un inhibidor de $\beta$-lactamasa. Ofrece cobertura para un amplio espectro antimicrobiano (especies grampositivas, gramnegativas y anaerobios estrictos) $)^{1,27}$. Actualmente está autorizada por la FDA para su uso en pacientes $\geq 2$ meses con apendicitis aguda, peritonitis, infecciones intraabdominales complicadas como ECN y bacteriemia por $\mathrm{BGN}^{2}$. Ha demostrado ser bien tolerada en RN de muy bajo peso al nacer, con efectos adversos limitados ${ }^{1,28}$. Es el cuarto AM más común recetado en la UCIN, y a pesar de su uso frecuente en $\mathrm{RN}$, se sabe poco sobre su seguridad en estos pacientes ${ }^{27}$.

Debido a que el fármaco se elimina principalmente por filtración glomerular y secreción tubular, se espera que el aclaramiento se vea afectado por la maduración de la función renal en neonatos ${ }^{1}$.

Una estrategia de dosificación basada en EPM explica los cambios en la disposición de piperacilina/tazobactam durante el primer mes del neonato y así permite alcanzar objetivos terapéuticos en $>90 \%$ de los lactantes, independientemente de la CIM del microorganismo, en comparación con esquemas de dosificación que sólo alcanzaron $<70 \%$ del objetivo ${ }^{1,8}$.

En contraste con los estudios de adultos, que apoyan una infusión prolongada para el tratamiento de infecciones altamente resistentes, en esta población no se observó beneficio terapéutico adicional al utilizar esta estrategia, probablemente debido a la lentitud de su eliminación, que da lugar a concentraciones terapéuticas para la mayor parte del intervalo de dosificación ${ }^{1}$.

Dosificación recomendada de piperacilina/tazobactam en neonatos en la Tabla 6 . activos, en fase II, en pacientes pediátricos de 3 meses 18 años, con infecciones complicadas del tracto urinario o infecciones intra-abdominales complicadas ${ }^{26}$.

El único estudio publicado en pacientes bajo 5 años de edad, que incluye neonatos de hasta 13 días de vida y de 25 semanas de EG al nacer, utilizó indistintamente, para todos, la misma dosificación de $62,5 \mathrm{mg} / \mathrm{kg} / \mathrm{dosis}$, administrado cada $8 \mathrm{~h}^{26}$. Este estudio abarcó un $\mathrm{n}$ pequeño de ocho pacientes; sin embargo, es el único estudio que

\section{Carbapenémicos}

\section{Meropenem}

En su calidad de $\beta$-lactámico, inhibe la formación de la pared celular bacteriana gracias a su alta afinidad por las proteína de unión a penicilina (sigla en inglés: PBP) 
del tipo 2, 3 y 4, propiedad que le confiere mayor espectro de acción que la penicilinas y cefalosporinas y mayor estabilidad frente a $\beta$-lactamasas de amplio espectro.

Meropenem tiene actividad contra una amplia variedad de bacterias gramnegativas, grampositivas y anaerobios estrictos, es bien tolerado en $\mathrm{RN}$ (incluyendo prematuros) y permite utilizar monoterapia en lugar de terapia combinada ${ }^{1,29}$.

En neonatos, se prescribe para infecciones intra-abdominales complicadas (consideradas polimicrobianas), ECN y sepsis causadas por patógenos gramnegativos resistentes y anaerobios estrictos.

Actualmente está aprobado por la FDA para su uso en niños $\geq 3$ meses de edad con MBA y/o infecciones intraabdominales como terapia de segunda línea; sin embargo, existe un uso sustancial no autorizado de meropenem en lactantes $<3$ meses de edad, a pesar de la falta de datos adecuados de dosificación, seguridad y eficacia en este grupo $^{2,30}$.

Para abordar la brecha en el conocimiento en pacientes $<3$ meses se han realizado estudios multicéntricos que han logrado determinar sus propiedades y perfil de seguridad en estos lactantes ${ }^{2}$. En estos estudios, relativamente recientes, no aleatorizados, se ha descrito una tasa de éxito global de $84 \%$ en infecciones abdominales sospechosas o confirmadas, cumpliendo con la definición de éxito terapéutico, siendo más alta en niños $\geq 32$ semanas $^{30}$.

Meropenem se indica también para MBA, ya que puede alcanzar concentraciones tan altas en el SNC como $25 \%$ de las CP y con una penetración en el LCR de hasta $70 \%{ }^{1,2}$. Recientemente se ha evaluado en neonatos la FC de diferentes regímenes de dosificación de meropenem. El estudio más grande al respecto reclutó 188 neonatos (incluidos prematuros) y encontró que un régimen de dosificación que considera una combinación de EPM y la creatininemia puede lograr una exposición óptima al fármaco ${ }^{1}$.

La administración convencional de meropenem es mediante una infusión de $30 \mathrm{~min}$, ya que algunos datos indican una rápida degradación después de su reconstitución $^{29}$; sin embargo, estudios previos demostraron que su actividad bactericida depende de la fracción de tiempo que el fármaco libre excede la CIM del microorganismo respectivo, y por ello, la estrategia de infusión prolongada sería una alternativa en neonatos ${ }^{29}$. Shabaan AE y cols., publicaron un estudio sobre el uso de infusión prolongada de meropenem en RN con sepsis tardía por BGN, llegando a la conclusión que, esta modalidad se asoció, de forma estadísticamente significativa, con una mayor mejoría clínica y erradicación microbiológica, así como con una menor mortalidad neonatal, requerimiento de soporte ventilatorio e insuficiencia renal aguda, en comparación con la estrategia convencional ${ }^{29}$.
La sugerencia de régimen de dosificación actual sería de $20 \mathrm{mg} / \mathrm{kg} / \mathrm{dosis}$, administrada cada $8 \mathrm{~h}$, en la mayoría de los casos, y $40 \mathrm{mg} / \mathrm{kg} /$ dosis, administrada cada $8 \mathrm{~h}$, en MBA e infección por Pseudomonas sp. La infusión debe ser durante 3-4 h, ya que, en este tiempo, meropenem logra CP más altas en neonatos, lo que puede ser favorable en el tratamiento de microorganismos con aumento de la CIM ${ }^{29}$.

Hay que considerar la estabilidad del producto que se va a administrar, ya que este estudio utilizó el producto innovador (original), el que tiene una estabilidad más prolongada que otras formulaciones.

Debido a las preocupaciones sobre las altas tasas de enterobacterias productoras de BLEE, se recomienda que meropenem se reserve para neonatos prematuros gravemente enfermos con sospecha o confirmación de sepsis tardía por BGN, especialmente en las UCIN en las que circulan microorganismos que producen BLEE o resistencias de otro tipo a las cefalosporinas de tercera generación ${ }^{31}$.

Dosificación recomendada de meropenem en neonatos en la Tabla 7.

\section{Aminoglucósidos}

Son AM que actúan inhibiendo la síntesis de proteínas uniéndose a la subunidad ribosómica $30 \mathrm{~S}$ e interfieren con la unión del ARN de transferencia, dando como resultado una síntesis proteica deficiente ${ }^{1,5,33}$. Presentan un efecto bactericida que va a depender de la CP del AM sobre la CIM, siendo la respuesta clínica mucho mejor a mayor concentración por sobre la $\mathrm{CIM}^{1}$.

Para una terapia efectiva- esto es válido tanto para gentamicina como para amikacina- el factor más importante en el éxito del tratamiento de las infecciones por BGN es que la concentración máxima se encuentre entre 8 y 12 veces por sobre la CIM (en neonatos con 8 veces es suficiente), lo que otorga una tasa de respuesta clínica

\begin{tabular}{|cccc|}
\hline \multicolumn{4}{|c|}{ Tabla 7. Recomendación para la dosificación de meropenem } \\
\hline $\begin{array}{c}\text { Edad gestacional } \\
\text { (semanas) }\end{array}$ & $\begin{array}{c}\text { Edad postnatal } \\
\text { (días) }\end{array}$ & $\begin{array}{c}\text { Dosis de mantención } \\
\text { ( } \mathbf{m g} / \mathbf{k g} / \text { dosis) }\end{array}$ & $\begin{array}{c}\text { Intervalo de } \\
\text { las dosis (h) }\end{array}$ \\
$<32$ & $<14$ & 20 & 12 \\
& $\geq 14$ & 20 & 8 \\
$\geq 32$ & $<14$ & 20 & 8 \\
& $\geq 14$ & 30 & 8 \\
\hline Infección SNC o & Independiente EG & 40 & 8 \\
Pseudomonas & & \\
\hline Shabaan AE, Nour I y cols. ${ }^{29}$, Smith PB, Cohen-Wolkowiez M y cols. ${ }^{32}$. & \\
\hline
\end{tabular}


de $90 \%{ }^{5,7}$. La respuesta dependiente de la concentración respalda el uso de dosis más altas para alcanzar las concentraciones máximas.

Poseen, además, efecto post-antibiótico, que corresponde al período durante el cual el AM continúa suprimiendo el crecimiento bacteriano a pesar de las $\mathrm{CP}$ por debajo de la $\mathrm{CIM}^{34}$. Este efecto post-antibiótico, junto con su mecanismo bactericida, posibilitan su correcta administración con menor frecuencia ${ }^{1}$.

Recientemente se han estudiado estrategias de dosificación en intervalos prolongados que emplean dosis fijas o dosis individualizadas basadas en la EPM y la EPN en la UCIN. Las dosis de intervalo prolongado permiten que las concentraciones máximas y mínimas se mantengan dentro del rango terapéutico, lo que da como resultado un efecto post-antibiótico más prolongado y se traducen en una mejor respuesta clínica, minimizando la nefrotoxicidad asociada con las concentraciones mínimas supra-terapéuticas ${ }^{33,34}$. Además, la dosificación una vez al día de aminoglucósidos ha demostrado ser menos tóxica y más eficaz que la dosificación más frecuente en estudios observacionales en neonatos humanos ${ }^{34}$.

Los aminoglucósidos se eliminan casi exclusivamente por vía renal, con una tasa de eliminación muy variable $\mathrm{y}$ más prolongada en $\mathrm{RN}$ en comparación con niños $\mathrm{y}$ adultos $^{27,33}$

Aunque son ampliamente utilizados en la UCIN, todavía existe mucha discusión sobre su óptima dosificación, seguridad y eficacia ${ }^{33}$. Como son hidrofílicos, se distribuyen al compartimento de agua extracelular y se eliminan mediante filtración glomerular y esto significa que existe un argumento adicional para requerir dosis más altas (por mayor volumen de distribución), combinadas con intervalos de dosificación aún más extendidos (por menor aclaramiento renal en neonatos) ${ }^{5}$.

Todos los aminoglucósidos pueden causar ototoxicidad la que generalmente es irreversible, bilateral y simétrica, aunque hasta $20 \%$ de los pacientes mostrará alguna mejoría con el tiempo ${ }^{27}$. La cantidad de daño es directamente proporcional a la cantidad de exposición; es más profunda en aquellos pacientes con menos células ciliadas (ancianos o aquellos con lesión previa inducida por aminoglucósidos) y aquellos con pre-existencia de pérdida de audición. El daño es más intenso con dosis más altas acumuladas, independientemente del tipo de aminoglucósido utilizado ${ }^{27}$.

A diferencia de la ototoxicidad, la nefrotoxicidad es principalmente leve, transitoria y se desarrolla tarde en el curso de la terapia resolviéndose rápidamente una vez que el AM se interrumpe ${ }^{27}$. La toxicidad potencial de los aminoglucósidos está directamente relacionada con su afinidad de unión por la membrana del borde en cepillo del túbulo proximal a través del complejo de megalina ${ }^{27}$. Como $90 \%$ de los aminoglucósidos son eliminados por los riñones y filtrados por el glomérulo, la eliminación de estos fármacos se ve directamente afectada por la función renal del paciente ${ }^{35}$.

Estudios en neonatos de término y prematuros muestran consistentemente grados bajos de ototoxicidad y nefrotoxicidad, independientemente del régimen de dosificación ${ }^{27}$. La nefro y ototoxicidad clínicamente significativas en neonatos son muy inusuales. La evidencia sugiere que los RN prematuros y de bajo peso al nacer y los neonatos que han experimentado hipoxia tienen más probabilidades de experimentar un retraso transitorio en la caída fisiológica normal de la creatininemia cuando reciben aminoglucósidos, pero esto no tiene consecuencias clínicas adversas $^{27}$.

Uno de los primeros pasos en la distribución del aminoglucósido es su unión a las células renales, cocleares y membranas vestibulares. La absorción por estos tejidos es más eficiente con bajas concentraciones sostenidas, en comparación con altas concentraciones intermitentes, ya que éstas no conducen a una acumulación excesiva ${ }^{34}$. Un meta-análisis reveló que la dosificación de una vez al día mejora la eficacia clínica sin incrementar las tasas de oto y nefrotoxicidad. Este resultado se debe probablemente a la menor acumulación de los aminoglucósidos en el oído interno y túbulos renales ${ }^{2}$.

En un estudio de seguimiento de $800 \mathrm{RN}$, tres años después del alta de la UCIN, no se encontró una mayor incidencia de pérdida de audición en aquellos expuestos a aminoglucósidos, independientemente del peso al nacer, en comparación con aquellos que no recibieron estos $\mathrm{AM}^{27}$. En otra cohorte de 2.995 RN en E.U.A., evaluados por pérdida de audición, $1,7 \%$ de aquellos que recibieron $>5$ días de terapia con aminoglucósidos con otros factores de riesgo de hipoacusia, tuvieron pérdida auditiva permanente, en comparación con $1 \%$ de aquellos sin factores de riesgo identificables. Así, el estudio concluyó que no era posible relacionar la pérdida auditiva con la exposición a aminoglucósidos, dada la presencia de múltiples otros factores de riesgo y la baja prevalencia de pérdida de audición en aquellos que habían sido expuestos. Por tanto, en la actualidad, no existen pruebas claras de ototoxicidad atribuible en $\mathrm{RN}$ que recibieran aminoglucósidos ${ }^{27}$. Se concluye actualmente que la evidencia sobre oto y nefrotoxicidad relacionada con aminoglucósidos en RN son infrecuentes, independientemente del régimen de dosificación utilizado ${ }^{27}$. Las CP máximas elevadas, en general, no se han asociado con toxicidad, y este efecto es más común con la administración prolongada $(>10$ días) y CP valle elevadas ${ }^{7}$.

La duración de la terapia con aminoglucósidos debe limitarse a 5-7 días cuando sea posible, con el fin de reducir la acumulación del fármaco dentro de la endolinfa y el posterior daño de las células ciliadas. La contribución de la genética a la ototoxicidad no puede cuantificarse 
fácilmente $\mathrm{y}$, aunque se requieren ensayos grandes, se recomienda evitar los aminoglucósidos en $\mathrm{RN}$ con antecedentes familiares de posible sordera inducida por aminoglucósidos ${ }^{27}$.

\section{Gentamicina}

Gentamicina es uno de los aminoglucósidos más ampliamente usado para infecciones bacterianas graves en RN. Es rápidamente bactericida y eficaz contra la mayoría de los $\mathrm{BGN}^{2,7,34,36}$. Combinada con $\beta$-lactámicos, proporciona actividad sinérgica contra las bacterias más importantes causantes de la sepsis precoz como son $S$. agalactiae y L. monocytogenes ${ }^{34}$. La FDA autoriza su uso en la sepsis neonatal, así como en infecciones bacterianas del SNC, tracto urinario, vías respiratorias, piel/tejidos blandos e infecciones intra-abdominales graves ${ }^{2}$. En base a la evidencia actual de la FC de gentamicina, el régimen de una vez al día puede ser superior en el tratamiento de la sepsis en $\mathrm{RN}>32$ semanas de gestación ${ }^{34,37}$. Además, esta modalidad de dosificación se asoció con menores tasas de fracaso que el régimen de dosis múltiples ${ }^{34}$. Dadas sus ventajas, los regímenes de intervalo prolongado se utilizan ampliamente en las UCIN de todo el mundo ${ }^{2,7}$. Aunque la eficacia de gentamicina está relacionada con la CP máxima, las CP valle continuamente elevadas podrían causar toxicidad debido a la acumulación de gentamicina en los oídos y riñones ${ }^{36}$. Estas $\mathrm{CP}$ máximas se han relacionado con dos propiedades únicas de gentamicina: supresión continua del crecimiento bacteriano y disminución de la resistencia adaptativa ${ }^{7}$. La CP mínima de 0,5-2 $\mu \mathrm{g} / \mathrm{ml}$ se recomienda en la mayoría de los estudios en neonatos debido a que sobre ese valor existe riesgo potencial de toxicidad ${ }^{7,34-36}$.

Una creatininemia ligeramente elevada se ha asociado con 4,5 veces mayor probabilidad de tener una CP elevada de gentamicina ${ }^{34,35}$. Un reciente estudio realizó el seguimiento de 219 escolares (promedio de 9 años) expuestos a un régimen de gentamicina en dosis altas en el período neonatal, con audiometrías de tono puro a altas frecuencias, que son altamente sensibles y específicas para evaluar ototoxicidad, y no encontraron asociación entre la exposición a gentamicina e hipoacusia ${ }^{38}$. Los mecanismos detrás de la ototoxicidad inducida por gentamicina no se entienden del todo y actualmente, hay evidencia más fuerte de ototoxicidad por aminoglucósidos en niños mayores que en RN, debido a que éstos (pacientes con fibrosis quística o cáncer) reciben dosis acumulativas mayores que las que se administran comúnmente en neonatos. Alternativamente, el oído interno del RN es menos vulnerable a la ototoxicidad inducida por gentamicina, por lo que estos efectos pueden ser, en parte, reversibles ${ }^{38}$.

La mayoría de las indicaciones de gentamicina en la población neonatal son para el tratamiento de $\mathrm{RN}$ con sospecha de sepsis precoz y habitualmente se suspende luego de descartar el diagnóstico, dentro de 36 a 48 h. Si un régimen de una vez al día alcanza las $\mathrm{CP}$ máximas adecuadas mientras se evitan CP mínimas tóxicas, entonces las mediciones frecuentes de las CP de gentamicina no serían necesarias en estos cursos cortos hasta descartar la sepsis. Esto reduciría significativamente el costo hospitalario y la toma de muestras innecesarias en $\mathrm{RN}^{34}$.

Es imprescindible considerar dos situaciones importantes al momento de indicar la correcta dosificación: una es que la hipotermia afecta el aclaramiento de gentamicina, por lo cual se debe aumentar la frecuencia de dosificación para reducir la posibilidad de CP valle tóxicas en forma sustancial de 38 a 4\%, y otra es que el aumento de $14 \%$ en el volumen de distribución en RN sépticos implica que se pueden requerir dosis mayores para lograr concentraciones terapéuticas máximas en presencia de sepsis ${ }^{39}$.

Dosificación recomendada de gentamicina en neonatos en la Tabla 8

\section{Amikacina}

Las CP máximas y mínimas de amikacina se determinan 30 min después de la finalización de la infusión (post-dosis) y de 30 a 60 min antes de la siguiente dosis programada (pre-dosis), respectivamente ${ }^{33} \mathrm{y}$ basta pasar una dosis de amikacina para que en la siguiente dosis ya se pueda medir CP. Siempre deben tomarse CP si contamos con la CIM del patógeno, así evaluaremos con las CP pre-dosis la toxicidad y con los post-dosis la efectividad.

Un estudio previo sobre disfunción renal inducida por amikacina informó que el período de tratamiento total varió entre 10 y 14 días. En consecuencia, se debe prestar atención a la disfunción renal debida a la acumulación de amikacina con la administración a largo plazo $>10$ días ${ }^{49}$. Se determinó recientemente que la CP mínima de amikacina $\geq 10 \mu \mathrm{g} / \mathrm{mL}$ afecta significativamente la ototoxicidad en los RN, especialmente los lactantes con bajo y extremadamente bajo peso de nacimiento; es necesario monitorizar siempre la dosis y el intervalo de

\begin{tabular}{|cccc|}
\hline \multicolumn{4}{|c|}{ Tabla 8. Recomendación para dosificación de gentamicina } \\
\hline $\begin{array}{c}\text { Edad gestacional } \\
\text { (semanas) }\end{array}$ & $\begin{array}{c}\text { Edad postnatal } \\
\text { (días) }\end{array}$ & $\begin{array}{c}\text { Dosis de mantención } \\
\text { ( } \mathbf{m g} / \mathbf{k g} / \text { dosis) }\end{array}$ & $\begin{array}{c}\text { Intervalo de } \\
\text { las dosis (h) }\end{array}$ \\
$\leq 29$ & $0-7$ & 5 & 48 \\
& $8-28$ & 5 & 36 \\
$\geq 29$ & 5 & 24 \\
$30-34$ & $0-7$ & 5 & 24 \\
& $\geq 8$ & 5 & 24 \\
\hline & - & 5 & \\
\hline
\end{tabular}




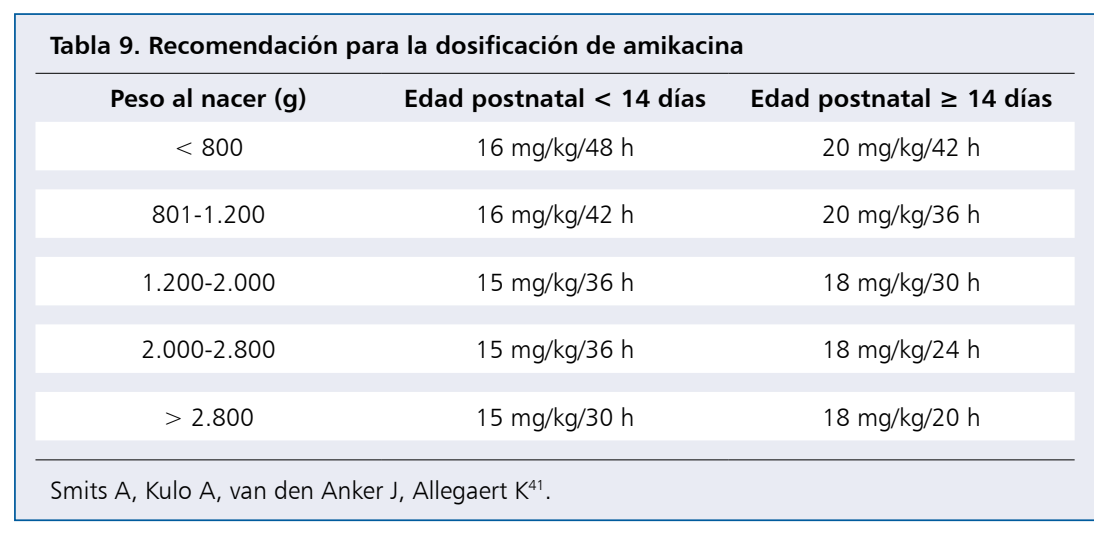

\begin{tabular}{|ccccc|}
\hline \multicolumn{4}{|c|}{ Tabla 10. Recomendación para la dosificación de metronidazol } \\
\hline Referencias & $\begin{array}{c}\text { Edad } \\
\text { postmenstrual } \\
\text { (semanas) }\end{array}$ & $\begin{array}{c}\text { Dosis } \\
\text { de carga } \\
\text { ( } \mathbf{m g} / \mathbf{k g})\end{array}$ & $\begin{array}{c}\text { Dosis de } \\
\text { mantención } \\
\text { (mg/kg/dosis) }\end{array}$ & $\begin{array}{c}\text { Intervalo } \\
\text { de las dosis } \\
\text { (h) }\end{array}$ \\
$* *$ & $24-25$ & 15 & 7,5 & 24 \\
& $26-27$ & 15 & 10 & 24 \\
& $28-33$ & 15 & 7,5 & 12 \\
$*$ & $34-40$ & 15 & 7,5 & 8 \\
& $>40$ & 15 & 7,5 & 6 \\
\hline **Suyagh M, Collier PS, Millership JS y cols. ${ }^{46} .{ }^{*}$ Cohen-Wolkowiez M, Ouellet D, Smith PB y cols. ${ }^{45}$. \\
\hline
\end{tabular}

administración ${ }^{49}$. En general, existe una toxico-dinámica madurativa favorable a los neonatos y registros históricos de cifras elevadas de daño renal y coclear en adultos en décadas previas fueron ocasionadas por la utilización de dosis múltiples ${ }^{41}$.

Dentro de las características farmacocinéticas de amikacina destaca su elevado volumen de distribución en neonatos, con una eliminación casi completa por filtración glomerular. El aclaramiento renal de amikacina depende de la EG, principalmente, pero hay factores como el peso y la EPN que también estarían involucrados en este parámetro FC. Cabe destacar que ibuprofeno es un fármaco que disminuye la eliminación renal de amikacina, por lo que, de usarse en forma concomitante, se recomienda extender el intervalo de dosificación de amikacina ${ }^{40,42}$.

Recientemente se desarrolló un estudio clínico prospectivo de modelo FC poblacional y regímenes de dosificación de amikacina para neonatos con edad postnatal de 1 a 30 días. El objetivo principal fue obtener $\mathrm{CP}$ mínimas de 1,5-3 $\mu \mathrm{g} / \mathrm{mL}$ y CP máximas de $>24 \mu \mathrm{g} / \mathrm{mL}$ en toda la población neonatal, lo cual dio como resultado las recomendaciones de dosificación para distintos pesos de nacimiento y EPN ${ }^{43}$. Con posterioridad se desarrolló y validó, prospectivamente, el mencionado régimen de dosificación, utilizando farmacometría y considerando el peso actual, la EPN, la asfixia perinatal y el uso de ibuprofeno, con leves modificaciones finales lo que permitió alcanzar mayor cumplimiento de los objetivos planteados, $71 \%$ con CP mínimas $<3 \mu \mathrm{g} / \mathrm{mL}$ y $90 \%$ con $\mathrm{CP}$ máximas de $>24 \mu \mathrm{g} / \mathrm{mL}$ y prácticamente $0 \%$ tuvo $\mathrm{CP}$ mínimas $>5 \mu \mathrm{g} / \mathrm{mL}$, consideradas tóxicas ${ }^{41}$.

Dosificación recomendada de amikacina en neonatos en la Tabla 9.

\section{Nitroimidazol}

\section{Metronidazol}

Metronidazol es un AM con actividad contra bacterias anaerobias estrictas gramnegativas y contra parásitos. Demuestra una destrucción dependiente de la concentración con un efecto post-antibiótico prolongado ${ }^{44}$. Se usa con frecuencia en combinación con otros AM en la población neonatal para el tratamiento de la ECN. Aunque metronidazol es el agente anaeróbico recomendado de elección para $\mathrm{RN}$ prematuros, hay datos limitados con respecto a su FC, dosificación, seguridad y eficacia en esta población de pacientes ${ }^{44}$. La dosificación actual está basada en EPM y las concentraciones terapéuticas se alcanzaron más adecuadamente, después de una dosis de carga el primer día de la terapia ${ }^{44,45}$. La vida media de eliminación es dos a tres veces más larga, y disminuye con el aumento de $\mathrm{EG}$ al nacer y $\mathrm{EPN}^{45}$. El régimen de dosificación actualmente sugerido está basado en EPM, lográndose el objetivo terapéutico en $90 \%$ cuando se comparó con los esquemas previamente publicados (The Harriet Lane Handbook y Neofax), en los cuales $<70 \%$ de los pacientes alcanzaron el objetivo $\mathrm{FD}^{44,45}$. El esquema de dosificación basado en EPM fue particularmente eficaz en lactantes más maduros entre 30-32 semanas y EPN $>60$ días. Parece prudente utilizar las recomendaciones de dosificación proporcionadas por Suyagh y cols. ${ }^{44}$ en pacientes $\leq 33$ semanas EPM y las recomendaciones de Cohen-Wolkowiez y cols. ${ }^{45}$ en pacientes $\geq 34$ semanas EPM. Sin embargo, debe tenerse en cuenta que estos estudios no evaluaron la eficacia clínica o los efectos adversos. Se necesitan estudios futuros para confirmar las CP necesarias para una mayor eficacia, limitando el desarrollo de eventos adversos ${ }^{44}$.

Dosificación recomendada de metronidazol en neonatos en la Tabla 10.

\section{Glicopéptidos}

\section{Vancomicina}

Vancomicina es un glicopéptido usado comúnmente contra microorganismos grampositivos resistentes como SARM, Enterococcus spp resistente a ampicilina y SCN resistente a meticilina ${ }^{1,47}$. 
Este AM se rige por el parámetro de FC/FD definido como AUC/CIM. Este parámetro se utiliza habitualmente para aquellos AM concentración-independiente, pero con efecto post-antibiótico prolongado ${ }^{4,48}$. En adultos el AUC/CIM en $24 \mathrm{~h}$, es el mejor predictor de óptimos resultados clínicos para el tratamiento con vancomici$\mathrm{na}^{1,48}$ siendo el valor $\geq 400$ aquel utilizado como objetivo terapéutico; este valor fue, obtenido luego de realizar estudios en pacientes adultos con neumonía por SARM. Sin embargo, no existen estudios en población pediátrica y menos en RN. En neonatos, que tienen predominio de infecciones por SCN, el AUC/CIM efectivo de vancomicina no ha sido estudiado profundamente y se cree que un valor más bajo puede ser razonable, ya que SCN raramente invade tejidos (donde las concentraciones de vancomicina son más bajas que en sangre), pero se necesitan más datos para respaldar esta recomendación ${ }^{49}$. Los SCN excepcionalmente causan infecciones diferentes a la bacteriemia ${ }^{1,50}$; por lo tanto, no hay datos disponibles para respaldar la necesidad de lograr un AUC/CIM de $\geq 400$ en $24 \mathrm{~h}^{51}$. Para lograr este valor, la CP mínima de vancomicina debiera ser $>10 \mu \mathrm{g} / \mathrm{mL}$ en $\mathrm{RN}^{47}$ suponiendo que la CIM del patógeno es $\leq 1 \mu \mathrm{g} / \mathrm{mL}^{48}$. La FC de vancomicina es muy variable entre los $\mathrm{RN}$ y se dispone de limitados datos, especialmente para neonatos $\leq 1.500 \mathrm{~g}$. Estas diferencias están, en gran medida, determinadas por el cambio en la cantidad de agua corporal y la maduración de la función renal en las primeras semanas de vida, tanto en neonatos prematuros como los nacidos de término ${ }^{47}$. Siendo vancomicina un AM hidrofílico, en neonatos influye el contenido total de agua corporal y el volumen de líquido extracelular, ya que éste es mayor en $\mathrm{RN}$, especialmente aquellos con bajo peso al nacer ${ }^{47}$. La FC de vancomicina en neonatos es muy variable debido a sus grandes diferencias en el peso y maduración, siendo común en la práctica clínica la heterogeneidad en los grados de exposición a vancomicina en este grupo de pacientes $^{51}$. Se ha demostrado que con el régimen de dosificación de NeoFax actualmente recomendado, la meta de $\mathrm{AUC} / \mathrm{CIM} \geq 400^{49}$ es alcanzable en menos de la mitad de los neonatos infectados; sólo $25 \%$ de ellos alcanza la CP mínima objetivo de 10 a $20 \mu \mathrm{g} / \mathrm{mL}$ y casi $20 \%$ tiene $\mathrm{CP}$ valle marcadamente bajas $(<5 \mu \mathrm{g} / \mathrm{mL})$, sugiriendo que las recomendaciones actuales de dosificación en NeoFax pueden no ser adecuadas para el tratamiento de la sepsis neonatal por SCN, con especial referencia al grupo $<29$ semanas $^{50-52}$. Otro factor a considerar, comunicado recientemente por Klahn y cols. ${ }^{53}$, fue que para predecir la probabilidad de lograr el objetivo AUC/ $\mathrm{CIM} \geq 400$, no sólo basta alcanzar CP adecuadas, sino que también influye la CIM de SCN para vancomicina observadas en cada institución. En este trabajo se concluyó que con la distribución de CIM locales (mediana 1 $\mu \mathrm{g} / \mathrm{mL}$ ), el objetivo terapéutico se alcanzó en sólo $47 \%$ de los casos. Considerando que, en general, la mediana de CIM es $1 \mu \mathrm{g} / \mathrm{mL}$ y que en muchos centros hospitalarios hasta $38 \%$ de los aislados de SCN tienen CIM $\geq 2 \mu \mathrm{g} / \mathrm{mL}$, nos enfrentamos a una clara dificultad de alcanzar el objetivo terapéutico; más aún, con las dosis recomendadas en NeoFax. La importancia de considerar las CIM locales de cada centro para hacer el cálculo de dosis empírica de vancomicina en neonatos ya ha sido planteado en varios recientes estudios asiáticos ${ }^{48}$. Se han emitido varias recomendaciones de dosificación, pero la mayoría de ellas no han sido validadas prospectivamente $\mathrm{y}$, actualmente no hay consenso sobre el régimen de dosificación inicial más apropiado para vancomicina, a pesar de ser uno de los AM más estudiados en $\mathrm{RN}^{52,54}$. Por lo anterior, se han creado muchísimos programas computacionales (software) que calculan en forma instantánea la dosis de vancomicina y que consideran todas las variables que influyen en el neonato. Una de las más recientes aplicaciones y de las más recomendables, además de ser gratuita, se llama NeoVanco y utiliza tres características clínicas fácilmente disponibles (= peso, EPM y creatininemia) y se puede implementar de manera fácil y uniforme en la práctica clínica a través de la Web (neovanco.insight-rx.com) ${ }^{51,55}$. Utilizando este calculador, $17 \%$ de los neonatos que lograron un AUC/ $\mathrm{CIM} \geq 400$ tuvieron una concentración mínima de $>15$ $\mu \mathrm{g} / \mathrm{mL}$ y en una cohorte de los $464 \mathrm{RN}$ que alcanzaron un $\mathrm{AUC} / \mathrm{CIM} \geq 400$ con la dosis de NeoVanco, $100 \%$ tenían una concentración mínima de $\geq 6 \mu \mathrm{g} / \mathrm{mL}^{51}$.

Pese a toda la problemática con respecto a la falla renal y vancomicina, este efecto adverso no se ha asociado con vancomicina sola, pero puede ocurrir en presencia de otros factores de riesgo reconocidos, incluido el ductus arterioso persistente (DAP), el uso concomitante de medicamentos anti-inflamatorios no esteroidales, bajo peso al nacer y puntajes más altos de gravedad y riesgo de mortalidad $^{49}$.

\section{Dosis de carga}

Cada vez toma más fuerza y fundamento la utilización de dosis de carga, debido a las ventajas en relación a lograr el objetivo terapéutico en forma efectiva y precoz, pudiendo mejorarlo desde 43 a $89 \%$, en especial, en aquellos neonatos $<29$ semanas (frecuentemente este grupo queda con dosis infra-terapéuticas $)^{52}$. En un reciente meta-análisis, el más grande publicado hasta ahora, que ha evaluado la FC de vancomicina en $\mathrm{RN}$, contemplando más de 15 estudios en siete diferentes países, confirmó que el régimen de dosificación óptimo de vancomicina debería incluir una dosis de carga ${ }^{52}$, ya que logra mejorar el objetivo terapéutico después de la primera dosis y en estado estacionario en todos los grupos de edad ${ }^{52}$. La dosis de carga se puede utilizar, tanto en la dosificación continua, como en la intermitente ${ }^{23,56}$. 


\begin{tabular}{|c|c|c|c|c|}
\hline $\begin{array}{l}\text { Edad } \\
\text { postnatal } \\
\text { (días) }\end{array}$ & $\begin{array}{c}\text { Peso } \\
\text { nacimiento } \\
\text { (gramos) }\end{array}$ & $\begin{array}{c}\text { Dosis } \\
\text { de carga } \\
\text { (mg/kg) }\end{array}$ & $\begin{array}{c}\text { Dosis de } \\
\text { mantención } \\
\text { (mg/kg/día) }\end{array}$ & $\begin{array}{l}\text { Intervalo de } \\
\text { las dosis } \\
\text { (h) }\end{array}$ \\
\hline $0-7$ & $\begin{array}{c}\leq 700 \\
701-1.000 \\
1.001-1.500 \\
1.501-2.500 \\
>2.500\end{array}$ & 16 & $\begin{array}{l}15 \\
21 \\
27 \\
30 \\
36\end{array}$ & $\begin{array}{l}8 \\
8 \\
8 \\
6 \\
6\end{array}$ \\
\hline $8-14$ & $\begin{array}{c}\leq 700 \\
701-1.000 \\
1.001-1.500 \\
1.501-2.500 \\
>2.500\end{array}$ & 20 & $\begin{array}{l}21 \\
27 \\
36 \\
40 \\
48\end{array}$ & $\begin{array}{l}8 \\
8 \\
8 \\
6 \\
6\end{array}$ \\
\hline $15-28^{*}$ & $\begin{array}{c}\leq 700 \\
701-1.000 \\
1.001-1.500 \\
1.501-2.500 \\
>2.500\end{array}$ & 23 & $\begin{array}{l}24 \\
42 \\
45 \\
52 \\
60\end{array}$ & $\begin{array}{l}8 \\
8 \\
8 \\
6 \\
6\end{array}$ \\
\hline
\end{tabular}

Tabla 12. Ajuste para la dosificación intermitente de vancomicina

$\begin{array}{ccc}\text { Régimen actual } & \text { Nivel basal }<\mathbf{1 0} \boldsymbol{\mu} \mathbf{g} \mathbf{m L}^{*} & \text { Nivel basal }>\mathbf{2 0} \boldsymbol{\mu} \mathbf{g} \mathbf{m L}^{* *} \\ \mathrm{c} / 6 \mathrm{~h} & \mathrm{c} / 4 \mathrm{~h} & \mathrm{c} / 8 \mathrm{~h} \\ \mathrm{c} / 8 \mathrm{~h} & \mathrm{c} / 6 \mathrm{~h} & \mathrm{c} / 12 \mathrm{~h} \\ \mathrm{c} / 12 \mathrm{~h} & \mathrm{c} / 8 \mathrm{~h} & \mathrm{c} / 18 \mathrm{~h} \\ \mathrm{c} / 18 \mathrm{~h} & \mathrm{c} / 12 \mathrm{~h} & \mathrm{c} / 24 \mathrm{~h} \\ \mathrm{c} / 24 \mathrm{~h} & \mathrm{c} / 18 \mathrm{~h} & \mathrm{c} / 30 \mathrm{~h}\end{array}$

*Se mantiene el valor de $<10 \mu \mathrm{g} / \mathrm{mL}$ respetando la tabla original, sin embargo, en base a la evidencia y a lo descrito en este manuscrito, debería considerarse con un valor de $<7 \mu \mathrm{g} / \mathrm{mL}$. ${ }^{*}$ Si la CP es $>20 \mu \mathrm{g} / \mathrm{mL}$, se suspende una dosis, se retoma a la dosis subsiguiente y luego de ello se cambia el intervalo a una frecuencia más espaciada, según la tabla. Debiera repetirse una medición de CP basal antes de cada dosis hasta lograr CP óptimas (si es posible). Una vez que la CP de vancomicina es $\leq 20 \mu \mathrm{g} / \mathrm{mL}$, la dosis se reinicia a una frecuencia más baja. Gwee A, Cranswicky N y cols. ${ }^{58}$

Tabla 13. Recomendación para dosificación continua de vancomicina

$\begin{array}{cccc}\begin{array}{c}\text { Creatinina sérica } \\ (\mathbf{m g} / \mathbf{d L})\end{array} & \begin{array}{c}\text { Edad gestacional } \\ \text { corregida (semanas) }\end{array} & \begin{array}{c}\text { Dosis de carga } \\ (\mathbf{m g} / \mathbf{k g})\end{array} & \begin{array}{c}\text { Dosis mantención } \\ (\mathbf{m g} / \mathbf{k g} / \mathbf{d i ́})\end{array} \\ <0,45 & \geq 40 & 15 & 50 \\ <0,45 & <40 & 15 & 40 \\ 0,45-0,68 & \text { Todas } & 15 & 30 \\ >0,68 & \text { Todas } & 15 & 20\end{array}$

Gwee A, Cranswick N y cols. ${ }^{58}$.

Tabla 14. Ajuste para dosificación continua de vancomicina

Adjuste dosis (mg/día): Se calculará por la última dosis de mantenimiento $X$

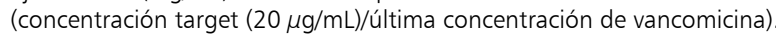

Gwee A, Cranswick N y cols. ${ }^{58}$.
La Tabla 11, reúne la mejor información hasta la fecha, para la recomendación de dosificación empírica e intermitente, con dosis de carga para vancomicina.

La Tabla 12 muestra los ajustes en la frecuencia de administración de vancomicina, según las concentraciones basales logradas con las dosis inicialmente indicadas.

\section{Dosificación continua}

Hasta hace no mucho tiempo, aún existía incertidumbre sobre la utilización de dosis continua en la población neonatal; sin embargo, varios estudios, mediante simulaciones de Monte Carlo, concluyeron que la dosificación continua fue más ventajosa por sobre la administración intermitente para la mayoría de los $\mathrm{RN}$, tanto nacidos de término como prematuros, cuando se trataban de infecciones causadas por microorganismos con CIM superiores. Los regímenes de dosificación continua (con dosis de carga) alcanzaron $\mathrm{AUC} / \mathrm{CIM} \geq 400$ en las primeras $24 \mathrm{~h}$ de tratamiento, a diferencia del régimen intermitente ${ }^{57}$. Otras ventajas de la administración continua son: mayor eficacia bactericida ya que permite alcanzar más precozmente y en forma constante las concentraciones objetivo del fármaco ${ }^{57}$, requiriendo dosis totales más bajas, reduciendo la toxicidad $\mathrm{y}$, además, necesitando menos muestras para el monitoreo de $\mathrm{CP}^{58}$, todo lo cual lleva a tener mayor tasa de éxito ${ }^{2,59}$. La infusión continua es una estrategia a plantearse, en especial, en pacientes quienes, a pesar de utilizar altas dosis, logran CP basales bajas (entendido como $\leq 5 \mu \mathrm{g}$ / $\mathrm{mL}$ ) sumado a una falta de control de la infección ${ }^{59}$. La Tabla 13 muestra las sugerencias de dosificación continua de vancomicina en neonatos.

La Tabla 14 muestra los ajustes de dosis diaria de vancomicina, administrada en forma continua, para lograr una concentración plasmática óptima.

\section{Dosis intermitente versus dosis continua}

Un reciente estudio randomizado, controlado, que comparó dosis intermitente versus dosis continua de vancomicina, concluyó que el logro de CP objetivo de vancomicina ( 84 versus $97 \%$ ), el tiempo promedio en alcanzar la CP objetivo (33,6 h versus $27,1 \mathrm{~h}$ ) y el tiempo promedio en negativizar los hemocultivos $(55,3 \mathrm{~h}$ versus $46,1 \mathrm{~h}$ ), fue significativamente mejor en aquellos pacientes con dosis continua, resultando en un menor ajuste de dosis y una dosis diaria media más baja ${ }^{49,58}$.

\section{Monitorización de concentraciones plasmáticas}

Se considera fundamental la monitorización de CP ante la dificultad en alcanzar CP óptimas terapéuticas, en particular en los neonatos, debido a la rápida maduración de la función renal que ocurre en las primeras semanas ${ }^{49}$. La monitorización de la $\mathrm{CP}$ de vancomicina se realiza actualmente para evitar complicaciones de toxicidad y también para evitar CP excesivamente bajas que podrían 
reducir la eficacia de la terapia y aumentar la propensión a la resistencia bacteriana ${ }^{47,49}$.

En la mayoría de los casos bastaría con $\mathrm{CP}$ valle o pre dosis; sin embargo, en infecciones de difícil manejo, como bacteriemia persistente o compromiso de SNC se sugiere las CP pre y post-dosis. Las CP pre-dosis deben ser tomadas previo a la cuarta dosis y las post-dosis 60 min después de terminada la infusión de la cuarta dosis $^{58}$. Si la CP mínima de vancomicina fue $<10 \mu \mathrm{g} / \mathrm{mL}$ o $>20 \mu \mathrm{g} / \mathrm{mL}$, después del ajuste de la dosis, se debieran tomar CP mínima y máxima antes y después de la tercera dosis ajustada ${ }^{58}$. A pesar de que se podrían considerar en neonatología CP terapéuticas pre-dosis de 7-11 $\mu \mathrm{g} / \mathrm{mL}$, ya que son altamente predictoras de AUC/CIM $\geq 400$ en $90 \%$ de los neonatos, se ha visto que una CP mínima por sí sola no predice con precisión el AUC y se necesitan cálculos con enfoques bayesianos ${ }^{49}$. Post-dosis se consideraría óptimo $30-40 \mu \mathrm{g} / \mathrm{mL}$. Si vancomicina fue administrada mediante infusión continua, se miden $\mathrm{CP}$ inmediatamente después de la dosis de carga y de 18 a 30 h después del comienzo de la infusión ${ }^{55,58}$, siendo las CP objetivo en estado estacionario $15-25 \mu \mathrm{g} / \mathrm{mL}^{49}$. El volumen de muestra necesario para la medición de CP debiera ser validado y consensuado con el laboratorio de cada centro, para poder optimizar el examen en el menor volumen posible, siendo lo ideal muestras de $0,5 \mathrm{ml}$.

\section{Vancomicina y tratamiento del ductus arterioso persistente (DAP)}

En RN prematuros tratados concomitantemente con ibuprofeno para tratamiento del DAP, con sospecha o confirmación de sepsis tardía, se ha informado una disminución de $16 \%$ en el aclaramiento de vancomicina; en el caso de indometacina, disminuye hasta 55\%. En base a estos hallazgos, se han propuestos los ajustes de dosis con el fin de garantizar un tratamiento seguro y efectivo para estos pacientes ${ }^{60}$. La Tabla 15 muestra la sugerencia de dosificación en caso de que el RN esté con tratamiento para el DAP, tanto que sea con ibuprofeno ó con indometacina.

La dosificación terapéutica debiera ser guiada por AUC y la monitorización de $\mathrm{CP}$, preferiblemente con estimación bayesiana ya que, está demostrado que pueden lograr la exposición objetivo a vancomicina, necesaria para un resultado exitoso para todos los $\mathrm{RN}$, independientemente de la edad gestacional y edad cronológica ${ }^{49}$.

\section{Sulfas}

\section{Cotrimoxazol}

Cotrimoxazol es una combinación de trimetoprim (TMP), un análogo de pirimidina, y sulfametoxazol (SMX), una sulfa de acción intermedia, perteneciente a la familia de las sulfonamidas. Ambos componentes actúan secuencialmente en dos pasos sucesivos en la biosíntesis de ácidos nucleicos bacterianos. Cotrimoxazol se usa en pediatría para el tratamiento y la prevención de diversas afecciones clínicas, incluidas algunas infecciones del tracto urinario y la neumonía por Pneumocystis jirovecii. Aunque cotrimoxazol no está aprobado en neonatos por la FDA, se recomienda para el tratamiento de infecciones

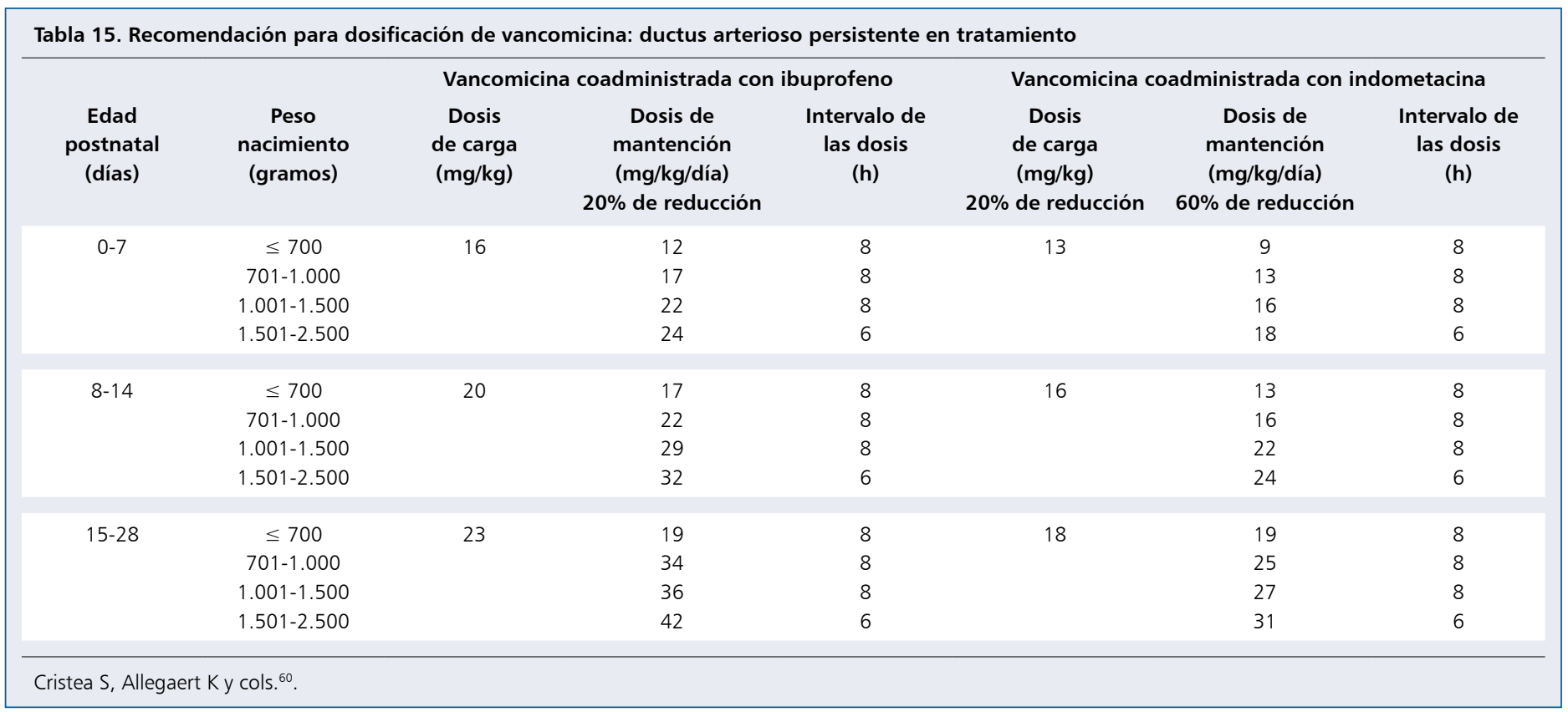




\section{Macrólidos}

ambulatorios con infecciones de piel y tejidos blandos causados por $S$. aureus resistente a meticilina adquirido en la comunidad (SARM-AC) ${ }^{61}$.

El clásico estudio de $1982^{62}$, con una cohorte de RN de término y pretérmino, mostró como resultados FC que TMT tiene un volumen de distribución mucho mayor que SMX y ambos tienen una vida media que no dependía del aclaramiento de creatinina. El esquema posológico recomendado se basó en la probable asociación entre uso de cotrimoxazol y kernicterus y fue de $3 \mathrm{mg} / \mathrm{kg}$ de carga y $1 \mathrm{mg} / \mathrm{kg} /$ dosis, administrado cada $12 \mathrm{~h}$ (en base a TMT); lo interesante es que existe un reporte de un caso de un neonato con sepsis por Stenotrophomonas maltophilia en quien se ocuparon las dosis antes mencionadas y hubo falla terapéutica, por lo cual finalmente se terminó utilizando $15 \mathrm{mg} / \mathrm{kg} /$ día de TMT, fraccionado cada $6 \mathrm{~h}^{63}$. Con respecto a la asociación entre uso de cotrimoxazol y la aparición de kernicterus, cabe mencionar que es muy baja, debido a que, las concentraciones que se necesitan para que sulfametoxazol desplace a la bilirrubina de su unión a la albumina son 50 veces por sobre las $\mathrm{CP}$ que se obtienen con las dosis habituales. Además, SMX se une solamente en $60 \%$ a la albúmina, lo que lo hace más ineficiente en generar un desplazamiento de la bilirrubina desde su unión a albúmina; esto, sumado a que su volumen de distribución es mucho menor, hacen plantear que la posible aparición de kernicterus no es un factor que contraindique el uso de dosis más elevadas de cotrimoxazol en neonatos ${ }^{64}$.

Considerando que el mayor uso que se da en neonatología es para el tratamiento de casos aislados o brotes por $S$. maltophilia, que la probabilidad de kernicterus es baja y que existe riesgo de falla terapéutica con dosis menores, se deberían considerar dosis más elevadas que las recomendadas por Springer C y cols. ${ }^{62}$.

Un reciente estudio sobre FC/FD en $<6$ años sugiere una dosis $12 \mathrm{mg} / \mathrm{kg}$ /día del componente de TMP, fraccionado cada $12 \mathrm{~h}$, siendo adecuado para la mayoría de las infecciones -a excepción de RN prematuros, en quien debe utilizarse $15 \mathrm{mg} / \mathrm{kg} /$ día del componente de TMP, fraccionado cada $12 \mathrm{~h}$ - para cumplir con el objetivo FD y lograr el óptimo tratamiento de $P$. jirovecii ${ }^{61}$.

Dosificación recomendada de cotrimoxazol en neonatos en la Tabla 16.

Tabla 16. Recomendación para la dosificación de cotrimoxazol

\begin{tabular}{|c|c|c|}
\hline $\begin{array}{l}\text { Edad gestacional } \\
\text { (semanas) }\end{array}$ & $\begin{array}{c}\text { Dosis de mantención } \\
\text { (mg/kg/día) }\end{array}$ & $\begin{array}{l}\text { Intervalo de las dosis } \\
\text { (h) }\end{array}$ \\
\hline Todas* & $12^{* *}$ & 12 \\
\hline
\end{tabular}

*Menores de 6 años. **Para Pneumocystis jirovecii 15 mg/kg (también cada 12 h), a excepción de prematuros. Autmizguine J, Melloni C y cols. ${ }^{61}$

\section{Azitromicina}

Azitromicina es un azálido derivado de eritromici$\mathrm{na}^{65,66}$. Ha demostrado actividad in vitro e in vivo en modelos experimentales contra Ureaplasma urealyticum ${ }^{66}$ y actividad intracelular en casos de conjuntivitis por Chlamydia trachomatis ${ }^{67}$. La vida media se estima entre 26 y $83 \mathrm{~h}$ en neonatos, llegando a ser de $69 \mathrm{~h}$ para neonatos de $1.000 \mathrm{~g}^{65}$. Las indicaciones establecidas para su uso en el período de $\mathrm{RN}$ incluyen: conjuntivitis y neumonía por C. trachomatis, tratamiento/profilaxis contra Bordetella pertussis ${ }^{68}$, neumonía por U. urealyticum.

Se ha demostrado que la dosis de 10 o $20 \mathrm{mg} / \mathrm{kg} /$ día IV en neonatos de 24-28 semanas es segura; sin embargo, la dosis de $20 \mathrm{mg} / \mathrm{kg} /$ día resulta más efectiva en neumonía por Ureaplasma sp para erradicar este microorganismo desde el tracto respiratorio. Los modelos FC y un reciente estudio randomizado, doble ciego, controlado, han demostrado que la mayor eficacia sería dar dosis de 20 $\mathrm{mg} / \mathrm{kg} /$ día durante tres días ${ }^{69}$, ya que, ayuda a favorecer el aclaramiento microbiológico y la erradicación, gracias a la mantención de CP de azitromicina por encima de la $\mathrm{CIM}_{50}$ hasta en $120 \mathrm{~h}$ post infusión endovenosa, sumado a su excelente concentración intra-fagocitaria, permitiendo una mejor llegada a tejidos especialmente pulmonar donde puede permanecer incluso más tiempo que en el plasma $^{65}$. Estos parámetros FC dan la base para utilizarla en cursos cortos de terapia, bastando tres dosis de azitromicina para erradicar Ureaplasma ${ }^{65}$. Azitromicina posee, además, un efecto anti-inflamatorio e inmunomodulador bien descrito ${ }^{66,70}$ el que se cree, reduciría el riesgo de displasia broncopulmonar (DBP) a mediano plazo, siendo atractiva su utilización entre pediatras broncopulmonares y neonatólogos. Lo anterior ha llevado a su inadecuada indicación en diversas situaciones clínicas, trayendo con ello elevadas cifras de resistencia y alteraciones en la microbiota intestinal, la que no logra recuperarse hasta dos años posteriores a su empleo ${ }^{70,71}$. La evidencia consistente actual de su uso como inmunomodulador sólo está establecida para situaciones clínicas muy puntuales como son: fibrosis quística con infección por $P$. aeruginosa, pan-bronquiolitis difusa y bronquiolitis obliterante posttrasplante, sin tener un rol claro en la $\mathrm{DBP}^{71}$.

El CDC considera a azitromicina como el fármaco de elección para el tratamiento y la quimioprofilaxis de la infección por $B$. pertussis en neonatos, pese a que en estos casos existe escasa información en cuanto a su eficacia y seguridad ${ }^{72}$. En el caso de la conjuntivitis por C. trachomatis un meta-análisis reciente sugiere que, aunque la evidencia de tratamiento con eritromicina en dosis de $50 \mathrm{mg} / \mathrm{kg} /$ día por 14 días resulta en mayor cura que azitromicina, la mejor adherencia, el menor riesgo de estenosis hipertrófica del píloro (EHP) y la menor 
frecuencia de intolerancia gastrointestinal, influyen en la recomendación del tratamiento con azitromicina en este cuadro. Se requiere, sin embargo, más información para comparar estos tratamientos en forma directa ${ }^{73}$. La única revisión sistemática del uso de azitromicina en neonatos, analizó 11 artículos con un total de 473 RN. Tres de estos estudios se refieren a la FC (43 neonatos). Los eventos adversos más relevantes asociados fueron los gastrointestinales (vómitos, intolerancia alimentaria, dolor abdominal y diarrea), no documentándose eventos adversos mayores y representando un mejor perfil de seguridad que eritromicina $^{72}$. Se ha observado también que la exposición a azitromicina aumenta el riesgo de EHP, aunque este riesgo es menor que con eritromicina, siendo mayor la asociación si la exposición ocurre en las dos primeras semanas de vida ( 8 veces más) y persiste, aunque en menor grado, en niños entre 2 y 6 semanas de vida (3 veces más). Sin embargo, se requieren más estudios para determinar la relación entre el uso de azitromicina neonatal y la EHP ${ }^{68}$.

Dosificación recomendada de azitromicina en neonatos en la Tabla 17.

\section{Oxazolidinonas}

\section{Linezolid}

Es un AM de origen sintético derivado de las oxazolidinonas. Su mecanismo de acción está dado por la inhibición de la síntesis proteica, al fijarse al sitio $\mathrm{P}$ (23s) de la subunidad ribosomal 50S e impedir que se forme el complejo ribosoma-fMet-tRNA ${ }^{74}$. Su espectro de actividad es exclusivo para bacterias grampositivas, incluyendo a Enterococccus y Staphylococcus resistentes a vancomicina. Fue aprobado por la FDA en el año 2002 para su uso pediátrico.

La FC de linezolid fue evaluada en un estudio en neonatos con edad gestacional comprendida entre $25 \mathrm{y}$ 40 semanas, revelando que los parámetros FC eran muy similares a la FC de los pacientes pediátricos. Además, este estudio recalca que los pacientes menores de 8 días de vida tienen un aclaramiento menor que los mayores de 8 días $^{75}$.

En relación a la penetración de linezolid en los distintos tejidos, se encontró en el LCR en todos los pacientes neuro-quirúrgicos evaluados, concentraciones máximas y valle mayores a la CIM, por lo cual se puede concluir que linezolid logra concentraciones terapéuticas óptimas en el $\mathrm{SNC}^{76}$. Por otra parte, en el pulmón tiene una muy buena llegada logrando concentración similar a las plasmáticas.

La dosificación recomendada logra concentraciones efectivas para cocáceas grampositivas con CIM $<4 \mu \mathrm{g} / \mathrm{mL}$ Una de las características más atractivas de linezolid es que posee una formulación en suspensión oral la que logra una excelente biodisponibilidad, inclusive en neonatos ${ }^{75,77}$.

Una reciente publicación que incluye evaluación de neonatos prematuros, determinó que realizando los análisis FC en un modelo bi-compartamental con las dosis previamente recomendadas ${ }^{75}$, se lograba alcanzar el objetivo terapéutico de $\mathrm{AUC} / \mathrm{CIM}_{0-24 \mathrm{~h}}$ en $>80 \mathrm{a}>90 \%$ de los casos considerando una CIM de $1 \mu \mathrm{g} / \mathrm{mL}$. Si la CIM fuese de $2 \mu \mathrm{g} / \mathrm{mL}$, se debería aumentar su dosificación a $12 \mathrm{mg} / \mathrm{kg} / \mathrm{dosis}$ y administrarla cada $8 \mathrm{~h}$. En este estudio se pudo comprobar que fue muy bien tolerado y no se identificaron eventos adversos de mayor magnitud ${ }^{78}$.

Finalmente, con respecto a la seguridad de linezolid en neonatos, se han reportado aparición de neutropenia, leucopenia y trombocitopenia que están más asociadas al tiempo de tratamiento ( $\geq 14$ días) e hiperlactacidemia intensa, y alteraciones gastrointestinales más frecuentes en edades gestacionales inferiores $(<25$ semanas $)$. En todos los casos, los valores regresan a la normalidad luego de suspender el fármaco ${ }^{77-79}$. También se han descrito neuropatías periféricas u ópticas en adultos y niños; generalmente ocurren después de una exposición prolongada a linezolid ( $\geq 28$ días), aunque se reportó la producción de neuropatía óptica después de sólo 16 días de tratamiento en una mujer de 29 años $^{74}$. La neurotoxicidad puede no desaparecer después de retirar el fármaco ${ }^{74}$. Un reciente estudio retrospectivo que evaluó neonatos con mediana de edad de 26 semanas, concluyó que no existió discapacidad neurológica o muerte a los 18-21 meses en pacientes que recibieron linezolid durante el primer mes de vida ${ }^{74}$.

Dosificación recomendada de linezolid en neonatos en la Tabla 18.

\section{Tabla 17. Recomendación para dosificación de azitromicina

$\begin{array}{ccc}\text { Dosis } & \text { Intervalo de las } & \text { Comentarios } \\ (\mathrm{mg} / \mathrm{kg}) & \text { dosis }(\mathrm{h}) & \end{array}$ \\ 10 \\ 24 Tratamiento Bordetella pertussis por 5 días \\ 20 \\ 24 Conjuntivitis por Chlamydia trachomatis por 3 días \\ 20 \\ 24 \\ Neumonía por Ureaplasma urealyticum por 3 días}

Merchan LM, Hssan HE y cols. ${ }^{65}$, Viscardi RM, Othman AA y cols. ${ }^{66}$, Smith C, Egunsola O y cols. ${ }^{72}$, Zikic A, Schünemann $\mathrm{H}$ y cols. ${ }^{73}$.

\begin{tabular}{|cccc}
\hline $\begin{array}{c}\text { Tabla 18. Recomendación para la dosificación de linezolid } \\
\text { (semanas) }\end{array}$ & $\begin{array}{c}\text { Edad postnatal } \\
\text { (días) }\end{array}$ & $\begin{array}{c}\text { Dosis de mantención } \\
\text { (mg/kg/dosis) }\end{array}$ & $\begin{array}{c}\text { Intervalo de } \\
\text { las dosis }(\mathbf{h})\end{array}$ \\
$\leq 34$ & $\leq 7$ & 10 & 12 \\
$\geq 34$ & $>7$ & 10 & 8 \\
$\geq 35$ & - & 10 & 8 \\
\hline
\end{tabular}




\section{Polimixinas}

\section{Colistina sulfato}

Es un antimicrobiano antiguo desarrollado en 1947. Colistina (colistimetato de sodio), es un ciclopéptido compuesto por un anillo policatiónico unido a un ácido graso. Se caracteriza por su gran capacidad bactericida y bajo grado de resistencia, unido a su excelente actividad sobre BGN, incluidos los multi-resistentes (MDR). Fue ampliamente utilizado en la década de los 60 pero debido a su toxicidad (nefrotoxicidad y neurotoxicidad) fue reemplazado por los aminoglucósidos en la década de los $70^{80}$. Estudios más recientes en pacientes pediátricos críticamente enfermos, sin fibrosis quística, han demostrado una evolución favorable en 72 a $98 \%$ de los tratados ${ }^{81}$.

Colistina IV se ha administrado con seguridad y eficacia adecuada en neonatos, incluyendo $\mathrm{RN}$ prematuros y de muy bajo peso al nacer ${ }^{82-84}$. Recientemente, Çağan y cols. comunicaron una serie de 65 RN (72\% de prematuros) que requirieron uso de colistina IV. Utilizaron dosis de $5 \mathrm{mg} / \mathrm{kg} /$ día, divididos en tres dosis diarias, con una mediana de 15 días de uso. Los eventos adversos reportados fueron siete $(10,7 \%)$, tres de ellos presentaron nefrotoxicidad, definida como aumento de la creatininemia basal en $0,5 \mathrm{mg} / \mathrm{dl}$ o aumento de dos veces el valor desde el inicio del tratamiento, tres pacientes presentaron neurotoxicidad (convulsiones) y un paciente tuvo apnea ${ }^{85}$.

\begin{tabular}{|c|c|c|c|c|}
\hline CBA (mg) & CMS (mg) & MUI & Marca & Laboratorio \\
\hline 33,3 & 80 & 1 & Colomycin $^{\circledast}$ & Farmacias y Droguerías de Chile \\
\hline 100 & 254 & 3 & Colistina $^{\circledR}$ & Richet \\
\hline 32 & 77 & 1 & Colent $^{\circledast}$ & Mastercare \\
\hline 150 & 370 & 4,5 & Dicupal $^{\boxplus}$ & Pharmainvesti \\
\hline
\end{tabular}

CBA: colistina base activa; CMS: colistimetato de sodio; mg: miligramos; MUI: millones de unidades internacionales.

Tabla 20. Recomendación para dosificación de colistina

\begin{tabular}{cccc}
\hline Vía de administración & Dosis & Frecuencia & Observaciones \\
Endovenosa & 2,5 a $5 \mathrm{mg} / \mathrm{kg} / \mathrm{día}$ & Cada $8 \mathrm{~h}$ & $\begin{array}{c}\text { Uso excepcional } \\
\text { CBA }\end{array}$ \\
& & & $\begin{array}{c}\text { Siempre uso combinado } \\
\text { Diluir en } 3-5 \mathrm{ml} \text { de solución salina } \\
\end{array}$ \\
& & $\begin{array}{c}\text { Ajuste según función renal } \\
\text { Considerar dosis de carga }\end{array}$
\end{tabular}

Nakwan N, Chokephaibulkit K y cols. ${ }^{92}$. CBA: colistina base activa.
En la población pediátrica y neonatal se ha descrito una menor tasa de nefrotoxicidad que en los adultos, de presentación más tardía, alrededor del $10^{\circ}$ día, y reversible al descontinuar el tratamiento ${ }^{86-89}$. Se describen con frecuencia en RN trastornos hidroelectrolíticos como hipomagnesemia e hipokalemia, por lo que se recomienda control sistemático de ellos antes y durante la terapia ${ }^{90}$. Por lo descrito, es aconsejable un control de creatininemia, electrolitos plasmáticos y magnesemia basal y luego cada $72 \mathrm{~h}$ de uso de colistina, en particular en aquellos pacientes con otros factores de riesgo para nefrotoxicidad, como aquellos con función renal basal deteriorada y pacientes con uso de fármacos nefrotóxicos ${ }^{91}$. Es recomendable observar, además, la aparición de apneas o crisis convulsivas durante la administración.

Una reciente revisión del uso de colistina en neonatos evaluó 17 estudios clínicos (un estudio prospectivo, tres estudios retrospectivos de casos y controles, ocho estudios observacionales retrospectivos y cinco informes de casos), con un total de 312 RN (entre 1 y 116 días de vida). Los principales usos fueron en infecciones en contexto de sepsis/bacteriemia $(57,6 \%)$, neumonía asociada a ventilación mecánica $(34,3 \%)$ y compromiso de SNC $(6,1 \%)^{92}$. La respuesta clínica fue favorable a su uso en $75 \%$ de aquellos con sepsis.

Colistina nebulizada como monoterapia se utilizó con éxito en ocho RN prematuros, pero los datos disponibles son insuficientes para respaldar esta práctica; además, la disposición pulmonar del fármaco disminuye cuando existe ocupación alveolar; por ende, se debe administrar en combinación con colistina IV complementaria, pero no como monoterapia ${ }^{92}$.

El uso tópico en ventriculitis ha sido especialmente beneficioso, debido a que colistina penetra mal a través de la barrera hemato-encefálica, incluso habiendo meninges inflamadas, y no logra esterilizar el LCR. Además, colistina intratecal se somete a una hidrólisis espontánea pero no lineal; por ende, dado que la colistina IV puede ser ineficaz en el tratamiento de infecciones del LCR, es prudente tratar estas infecciones con colistina intratecal asociada a $\mathrm{IV}^{92}$.

En Chile existen cuatro registros para colistina. En algunos casos, el rótulo del producto se expresa en unidades internacionales (UI), como en el caso de Colomycin ${ }^{\circledR}$ y Colent ${ }^{\circledR}$ y en otros, se encuentra expresado como mg de colistina base activa (CBA) como es el caso de Dicupal ${ }^{\circledR}$ y Colistina ${ }^{\circledR}$. Estas diferentes presentaciones han provocado algunas confusiones por corresponder a diferentes formulaciones y rotulaciones que deben ser consideradas al momento de la prescripción y de la administración.

Presentaciones de colistina en Chile (Tabla 19).

Dosificación recomendada de colistina en neonatos en la Tabla 20. 


\section{Quinolonas}

\section{Ciprofloxacina}

Es una fluoroquinolona sintética, potente AM y bactericida contra un amplio espectro de bacterias gramnegativas y grampositivas. No se considera un tratamiento de primera línea en las guías actuales para la sepsis neonatal, pero se usa en infecciones graves causadas por Enterobacter spp. resistente al tratamiento estándar y cuando existe un mayor riesgo de meningitis y absceso cerebral secundario. Es usada en Europa off label en $25 \%$ de las UCIN, principalmente en casos de sepsis bacteriana por microorganismos resistentes ${ }^{93}$.

Su mecanismo de acción consiste en paralizar la replicación bacteriana mediante la unión con la enzima ADN girasa, un tipo de topoisomerasa II. Muestra actividad in vitro contra la mayoría de las bacterias patógenas gramnegativas y muchas grampositivas. Después de su administración IV, ciprofloxacina se distribuye ampliamente en la mayoría de los fluidos y tejidos corporales, con una alta penetración en el LCR y el SNC ${ }^{93,94}$. Hasta la fecha se han realizado pocos estudios FC en RN de término y prematuros y los pocos datos disponibles en niños y $\mathrm{RN}$ infectados, han mostrado que las concentraciones en LCR eran comparables a las CP de ciprofloxacina ${ }^{94}$. La filtración glomerular y la secreción tubular son los principales mecanismos de excreción renal y $>65 \%$ de ciprofloxacina se excreta inalterada por el riñón; dado que se elimina principalmente por vía renal, se espera que la maduración renal anatómica y funcional tenga una gran influencia en su aclaramiento y la dosificación ${ }^{93}$. En adultos, el parámetro AUC/CIM pareció ser el mejor predictor de resultados microbiológicos y clínicos, siendo el valor objetivo de 125 , el que se utilizó en RN. Los datos obtenidos por simulación de Monte Carlo determinaron que los parámetros que influyen en su comportamiento son: EG, EPM, peso actual, creatininemia y administración conjunta de agentes inotrópicos ${ }^{93}$.

El régimen de dosificación de ciprofloxacina en neonatos y lactantes bajo tres meses de edad se ha establecido en base a análisis $\mathrm{FC}^{93}$, y el único estudio $\mathrm{FC}$ realizado en RN prematuros "sépticos" concluyó que una dosis de $20 \mathrm{mg} / \mathrm{kg} /$ día, fraccionada cada $12 \mathrm{~h}$, sería efectiva para las infecciones por BGN comunes, excepto para las infecciones por $P$. aeruginosa y para las infecciones por $S$. aureus, por lo cual probablemente en estos dos últimos

\begin{tabular}{|ccc|}
\hline \multicolumn{2}{|c|}{ Tabla 21. Recomendación para la dosificación de ciprofloxacina } \\
\hline $\begin{array}{c}\text { Edad postmenstrual } \\
\text { (semanas) }\end{array}$ & $\begin{array}{c}\text { Dosis } \\
\text { (mg/kg/dosis) }\end{array}$ & $\begin{array}{l}\text { Intervalo de las dosis } \\
\text { (h) }\end{array}$ \\
$<34$ & 7,5 & 12 \\
$\geq 34$ & 12,5 & 12 \\
\hline Zhao W, Hill H, Le Guellec C, Neal T y cols, TINN Consortium ${ }^{93}$. Bradley JS, Nelson JD y cols. ${ }^{22}$. \\
\hline
\end{tabular}

casos debiera utilizarse otra opción terapéutica. Aunque este estudio fue bien realizado, no proporciona datos suficientes para establecer el programa de dosificación óptimo de ciprofloxacina en la sepsis neonatal ${ }^{94}$.

Dosificación recomendada de ciprofloxacina en neonatos en la Tabla 21 .

\section{Conclusiones}

La dosificación adecuada y certera de medicamentos en $\mathrm{RN}$ ha sido un desafío permanente debido a la escasez de datos confiables disponibles, lo que se debe a: preocupaciones éticas para la incorporación de neonatos a los estudios, escasa disponibilidad de pacientes, falta de diseño adecuado de los estudios clínicos realizados, falta de experiencia en simulación FC/FD neonatal y grandes volúmenes de sangre requeridos para los análisis de medición de CP. Históricamente, la dosificación neonatal se ha extrapolado de estudios en adultos y se ha ajustado en función del peso.

Esto, a menudo resulta en una dosis insuficiente (que conduce a fallas de eficacia) o una sobredosificación (que representa un mayor riesgo de toxicidad). Además, la seguridad suele ser más difícil de extrapolar a esta población que experimenta cambios rápidos de su desarrollo y para quienes los efectos adversos a largo plazo son difíciles de predecir. Enfatizamos la necesidad de evitar la extrapolación universal de las recomendaciones de dosificación de niños mayores y adultos a RN.

Con la información recolectada y expuesta, creemos acercarnos a una dosificación segura y eficaz en muchas de las indicaciones habituales del paciente neonatológico, apoyando de esta forma una adecuada gestión de AM. Sin embargo, mantenemos una alerta permanente a la espera de mayor información y evidencia en esta particular población de pacientes.

\section{Referencias bibliográficas}

1.- Rivera-Chaparro N D, Cohen-Wolkowiez M, Greenberg R G. Dosing antibiotics in neonates: review of the pharmacokinetic data. Future Microbiol 2017;12: 1001-16. doi: 10.2217/fmb2017-0058
2.- Johnson J K, Laughon M M. Antimicrobial agent dosing in infants. Clin Ther 2016; 38(9): 1948-60. doi: 10.1016/j.clinthera.2016.06.017.

3.- Thompson G, Barker C I, Folgori L, Bielicki J A, Bradley J S, Lutsar I, et al. Global shortage of neonatal and paediatric antibiotic trials: rapid review. BMJ Open 2017; 7 (10): e016293. doi: 10.1136/bmjopen-2017-016293.

4.- van Donge T, Bielicki J A, van den Anker J, Pfister M. Key Components for antibiotic dose optimization of sepsis in neonates and infants. Front. Pediatr 2018; 6: 325. doi: 10.3389/ fped.2018.00325.

5.- Smits A, Kulo A, van den Anker J, Allegaert 
$\mathrm{K}$. The amikacin research program: a stepwise approach to validate dosing regimens in neonates. Expert Opin Drug Metab Toxicol 2017; 13 (2): 157-66. https://doi.org/10.1080/17 425255.2017.1234606

6.- Tremoulet A, Le J, Poindexter B, Sullivan J E, Laughon M, Delmore P. Characterization of the population pharmacokinetics of ampicillin in neonates using an opportunistic study design Antimicrob Agents Chemother 2014; 58 (6): 3013-20. doi: 10.1128/AAC.02374-13.

7.- Sundaram A, Alshaikh B, Dersch-Mills D, Dobry J, Akierman A R, Yusuf K. Extendedinterval dosing of gentamicin in premature neonates born at $<32$ weeks' gestation and $>7$ days of age. Clin Ther 2017; 39 (6): 1233-41. doi: 10.1016/j.clinthera.2017.05.343.

8.- Cohen-Wolkowiez M, Watt K M, Zhou C, Bloom B T, Poindexter B, Castro L, et al. Developmental pharmacokinetics of piperacillin and tazobactam using plasma and dried blood spots from infants. Antimicrob Agents Chemother 2014; 58(5): 2856-65. doi: 10.1128/AAC.02139-13.

9.- Fuchs A, Li G, Van Den Anker J, Bielicki J. Optimising B-lactam dosing in neonates: a review of pharmacokinetics, drug exposure and pathogens. Curr Pharm Des 2017; 23 (38) 25: 5805-38 doi: 10.2174/1381612823666170925162143.

10.- Cies J J, Fugarolas K N, Moore W S 2nd, Mason R W, Menkiti O R. Population pharmacokinetics and pharmacodynamic target attainment of ampicillin in neonates with hypoxemic-ischemic encephalopathy in the setting of controlled hypothermia. Pharmacotherapy 2017; 37(4): 456-63. doi: 10.1002/phar.1916. Epub 2017 Mar 30.

11.- Puopolo K M, Lynfield R, Cummings J J; Committee on Fetus and Newborn; Committee on Infectious Diseases. Management of infants at risk for Group B Streptococcal disease. Pediatrics 2019; 144 (2). pii: e20191881. doi: 10.1542/peds.2019-1881. Epub 2019 Jul 8.

12.- https://www.lhsc.on.ca/nicu/cloxacillin (Último ingreso el 23 de julio de 2020).

13.- Sandoval A, Cofré F, Delpiano L, Izquierdo G, Labraña Y, Reyes A. Reposicionando la cloxacilina como antibioticoterapia empírica inicial de la sepsis tardía neonatal. Rev Chilena Infectol 2015; 32 (2): 182-9. doi: 10.4067/ S0716-10182015000300007.

14.- Leroux S, Roué J M, Gouyon J B, Biran V, Zheng $\mathrm{H}$, Zhao W, et al. A population and developmental pharmacokinetic analysis to evaluate and optimize cefotaxime dosing regimen in neonates and young infants. Antimicrob Agents Chemother 2016; 60(11): 6626-34. doi: 10.1128/AAC.01045-16.

15.- Chen X K, Shi H Y, Leroux S, Xu H Y, Zhou $\mathrm{Y}$, Zheng Y, et al. Penetration of cefotaxime into cerebrospinal fluid in neonates and young infants. Antimicrob Agents Chemother 2018; 62(4): e02448-17. doi: 10.1128/AAC.02448-17.

16.- Fick R B Jr, Alexander M R, Prince R A, Kasik $J$ E. Penetration of cefotaxime into respiratory secretions. Antimicrob Agents Chemother 1987; 31(5): 815-7. doi: 10.1128/aac.31.5.815.

17.- Clark R H, Bloom B T, Spitzer A R, Gerstmann D R. Empiric use of ampicillin and cefotaxime, compared with ampicillin and gentamicin, for neonates at risk for sepsis is associated with an increased risk of neonatal death. Pediatrics 2006; 117(1): 67-74. doi: 10.1542/peds.20050179 .

18.- Cotten M, McDonald S, Stoll B, Goldberg $\mathrm{R}$, Poole K, Benjamin K. The association of third-generation cephalosporin use and invasive candidiasis in extremely low birth-weight infants. Pediatrics 2006; 118 (2): 717-22. doi: 10.1542/peds.2005-2677.

19.- Kuppala V S, Meinzen-Derr J, Morrow A L, Schibler K R. Prolonged initial empirical antibiotic treatment is associated with adverse outcomes in premature infants. $\mathrm{J}$ Pediatr 2011; 159 (5): 720-5. doi: 10.1016/j. jpeds.2011.05.033. Epub 2011 Jul 23.

20.- Cotten C M, Taylor S, Stoll B, Goldberg R N, Hansen N I, Sánchez P J, et al; NICHD Neonatal Research Network. Prolonged duration of initial empirical antibiotic treatment is associated with increased rates of necrotizing enterocolitis and death for extremely low birth weight infants. Pediatrics 2009; 123 (1): 58-66. doi: 10.1542/peds.2007-3423.

21.- Salerno S N, Bernhardt J, Laughon M, Jhaveri R, Massaro M, González D. Pharmacokinetics of ceftaroline in a preterm infant with methicillin-resistant Staphylococcus aureus pneumonia. J Pediatric Infect Dis Soc 2018; 7 (4): 342-5. doi: 10.1093/jpids/pix084.

22.- Bradley J S, Nelson J D, Barnett E D, Cantey J B, Kimberlin D W, Palumbo P E, et al. Nelson's Pediatric Antimicrobial Therapy. 26th Edition. United State of America: American Academy of Pediatrics 2020.

23.- Tunkel A R, Hartman B J, Kaplan S L, Kaufman B A, Roos K L, Scheld W M, et al. Practice guidelines for the management of bacterial meningitis. Clin Infect Dis. 2004; 39 (9): 1267-84. doi: 10.1086/425368. Epub 2004 Oct 6.

24.- Bradley J S, Stone G G, Chan P L S, Raber S R, Riccobene T, Mas Casullo V, et al. Phase 2 study of the safety, pharmacokinetics and efficacy of ceftaroline fosamil in neonates and very young infants with late-onset sepsis. Pediatr Infect Dis J 2020; 39 (5): 411-8. doi: 10.1097/INF.0000000000002607.

25.- ClinicalTrials.gov. Study of blood levels of ceftaroline fosamil in children who are receiving antibiotic therapy in the hospital. Available at: https:// clinicaltrials.gov/ct2/show/ NCT01298843?term=NCT01298843\&rank=1.
(Accedido el 15 de marzo de 2019).

26.- Iosifidis E, Chorafa E, Agakidou E, Kontou A, Violaki A, Volakli E, et al. Use of ceftazidimeavibactam for the treatment of extensively drug-resistant or pan drug-resistant Klebsiella pneumoniae in neonates and children $<5$ years of age. Pediatr Infect Dis J 2019;38(8): 812-5. doi: 10.1097/INF.0000000000002344.

27.- Kent A, Turner M A, Sharland M, Heath P T. Aminoglycoside toxicity in neonates: something to worry about? Expert Rev Anti Infect Ther 2014; 12(3): 319-31. doi: $10.1586 / 14787210.2014 .878648$.

28.- Salerno S, Hornik C P, Cohen-Wolkowiez M, Smith P B, Ku L C, Kelly M S, et al. Use of population pharmacokinetics and electronic health records to assess piperacillintazobactam safety in infants. Pediatr Infect Dis J 2017; 36 (9): 855-9. doi: 10.1097/ inf.0000000000001610.

29.- Shabaan A E, Nour I, Elsayed Eldegla H, Nasef N, Shouman B, Abdel-Hady H. Conventional versus prolonged infusion of meropenem in neonates with gram-negative late-onset sepsis: a randomized controlled trial. Pediatr Infect Dis J. 2017; 36 (4): 358-63. doi: 10.1097/ INF.0000000000001445.

30.- Cohen-Wolkowiez M, Poindexter B, Bidegain M, Weitkamp J H, Schelonka R L, Randolph D A, et al. Safety and effectiveness of meropenem in infants with suspected or complicated intraabdominal infections. Clin Infect Dis 2012; 55 (11): 1495-502. doi: $10.1093 / \mathrm{cid} / \mathrm{cis} 758$.

31.- Lutsar I, Chazallon C, Trafojer U, de Cabre V M, Auriti C, Bertaina C, et al and NeoMero Consortium. Meropenem vs standard of care for treatment of neonatal late onset sepsis (NeoMero1): A randomised controlled trial. PLoS One 2020;15 (3): e0229380. doi: 10.1371/journal.pone.0229380. eCollection 2020.

32.- Smith P B, Cohen-Wolkowiez M, Castro L M, Poindexter B, Bidegain M, Weitkamp J H, et al. Population pharmacokinetics of meropenem in plasma and cerebrospinal fluid of infants with suspected or complicated intra-abdominal infections Pediatr Infect Dis J 2011; 30 (10): 844-9. doi: 10.1097/INF.0b013e31822e8b0b.

33.- Hughes K M, Johnson P N, Anderson M P, Sekar K C, Welliver R C, Miller J L. Comparison of amikacin pharmacokinetics in neonates following implementation of a new dosage protocol. J Pediatr Pharmacol Ther 2017; 22 (1): 33-40. doi: 10.5863/1551-677622.1.33.

34.- Rao S C, Srinivasjois R, Moon K. One dose per day compared to multiple doses per day of gentamicin for treatment of suspected or proven sepsis in neonates. Cochrane Database Syst Rev 2016; 12: CD005091. doi: 10.1002/14651858. CD005091.pub4.

35.- Antolik T L, Cunningham K J, Alabsi S, 
Reimer R A. Empirical gentamicin dosing based on serum creatinine levels in premature and term neonates. Am J Health Syst Pharm. 2017; 74 (7): 466-72. doi: 10.2146/ajhp160061.

36.- Blaabjerg A S, Kofoed P E, Dalegaard M C, Fenger-Gron J. A simple high-dose gentamicin regimen showed no side effects among neonates. Dan Med J 2017; 64 (6). pii: A5387. https://ugeskriftet.dk/files/scientific_article_ files/2018-08/a5387.pdf.

37.- Puia-Dumitrescu M, Bretzius O M, Brown N, Fitz-Henley J A, Ssengonzi R, Wechsler C S, et al. Evaluation of gentamicin exposure in the Neonatal Intensive Care Unit and hearing function at discharge. $\mathrm{J}$ Pediatr 2018; 203: 131-6. doi: 10.1016/j. jpeds.2018.07.101.

38.- Hemmingsen D, Mikalsen C, Hansen A R, Fjalstad J W, Stenklev N C, Klingenberg C. Hearing in schoolchildren after neonatal exposure to a high dose gentamicin regimen. Pediatrics 2020; 145 (2). pii: e20192373. doi: 10.1542/peds.2019-2373. Epub 2020 Jan 8.

39.- Lingvall M, Reith $D$, Broadbent R. The effect of sepsis upon gentamicin pharmacokinetics in neonates. Br J Clin Pharmacol 2005; 59: 54-61. http://dx.doi.org/10.1111/j.13652125.2005.02260.x.

40.- Endo A, Nemoto A, Hanawa K, Maebayashi Y, Hasebe Y, Kobayashi M, et al. Relationship between amikacin blood concentration and ototoxicity in low birth weight infants. J Infect Chemother 2019; 25 (1): 17-21. doi: 10.1016/j. jiac.2018.10.001.

41.- Smits A, Kulo A, van den Anker J, Allegaert K. The Amikacin Research Program: a stepwise approach to validate dosing regimens in neonates. Expert Opin Drug Metab Toxicol 2017; 13 (2): 157-66. doi: 10.1080/17425255.2017.1234606. Epub 2016 Sep 21

42.- Illamola S M, Colom H van Hasselt J G. Evaluating renal function and age as predictors of amikacin clearance in neonates: model-based analysis and optimal dosing strategies. Br J Clin Pharmacol 2016; 82(3): 793-805. doi: 10.1111/ bcp. 13016

43.- Smits A, De Cock R F W, Allegaert K, Vanhaesebrouck S, Danhof M, Knibbe C A J. Prospective evaluation of a model-based dosing regimen for amikacin in preterm and term neonates in clinical practice. Antimicrob Agents Chemother 2015; 59(10): 6344-51. doi: 10.1128/AAC.01157-15. Epub 2015 Jul 27.

44.- Dannelley J F, Martin E M, Chaaban H, Miller $\mathrm{J} \mathrm{L}$. Review of metronidazole dosing in preterm neonates. Am J Perinatol 2017; 34(9): 833-8. doi: 10.1055/s-0037-1599822.

45.- Cohen-Wolkowiez M, Ouellet D, Smith P B, James L P, Ross A, Sullivan J E, et al. Population pharmacokinetics of metronidazole evaluated using scavenged samples from preterm infants. Antimicrob Agents Chemother 2012; 56 (4): 1828-37. doi: 10.1128/ AAC.06071-11.

46.- Suyagh M, Collier P S, Millership J S, Iheagwaram G, Millar M, Halliday H L, et al. Metronidazole population pharmacokinetics in preterm neonates using dried blood-spot sampling. Pediatrics 2011; 127 (2): e367-74. doi: 10.1542/peds.2010-0807. Epub 2011 Jan 10 .

47.- Kato H, Hagihara M, Nishiyama N, Koizumi Y, Mikamo H, Matsuura K, et al. Assessment of optimal initial dosing regimen with vancomycin pharmacokinetics model in very low birth weight neonates. J Infect Chemother 2017; 23 (3):154-60. doi: 10.1016/j.jiac.2016.11.009.

48.- Tseeng S H, Lim C P, Chen Q, Tang C C, Kong S T, Ho P C. Evaluating the relationship between vancomycin trough concentration and 24-hour area under the concentrationtime curve in neonates. Antimicrob Agents Chemother. 2018; 62 (4). pii: e01647-17. doi: 10.1128/AAC.01647-17. Print 2018 Apr.

49.- Rybak M J, Le J, Lodise T P, Levine D P, Bradley J S, Liu C, et al. Therapeutic monitoring of vancomycin for serious methicillin-resistant Staphylococcus aureus infections: A revised consensus guideline and review by the American Society of HealthSystem Pharmacists, the Infectious Diseases Society of America, the Pediatric Infectious Diseases Society and the Society of Infectious Diseases Pharmacists. Am J Health Syst Pharm 2020; 77 (11): 835-64. doi: 10.1093/ajhp/ zxaa036.

50.- Padari H, Oselin K, Tasa T, Metsvaht T, Lõivukene K, Lutsar I. Coagulase negative staphylococcal sepsis in neonates: do we need to adapt vancomycin dose or target? BMC Pediatr. 2016; 16 (1): 206. doi: 10.1186/s12887. 016-0753-0.

51.- Frymoyer A, Stockmann C, Hersh A L, Goswami S, Keizer R J. Individualized empiric vancomycin dosing in neonates using a modelbased approach. J Pediatric Infect Dis Soc. 2019; 8 (2): 97-104. doi: 10.1093/jpids/pix109. [Epub ahead of print].

52.- Jacqz-Aigrain E, Leroux S, Thomson A H, Allegaert K, Capparelli E V, Biran V, et al. Population pharmacokinetic meta-analysis of individual data to design the first randomized efficacy trial of vancomycin in neonates and young infants. J Antimicrob Chemother 2019; 74 (8): 2128-38. doi: 10.1093/jac/dkz158.

53.- Klahn P, Martínez J P, Sandoval A. Dosificación empírica de vancomicina en neonatos: relación entre recomendación de dosis iniciales y relación área bajo la curva en $24 \mathrm{~h} /$ concentración inhibitoria mínima. Rev Chilena Infectol 2020; 37(2): 99-105. http://dx.doi.org/10.4067/s071610182020000200099
54.- Dao K, Guidi M, André P, Giannoni E, Basterrechea S, Zhao W, et al. Optimisation of vancomycin exposure in neonates based on the best level of evidence. Pharmacol Res 2020; 154: 104278. doi: 10.1016/j.phrs.2019.104278. Epub 2019 May 18.

55.- Tauzin M, Cohen R, Durrmeyer X, Dassieu G, Barre J, Caeymaex L. Continuous-infusion vancomycin in neonates: assessment of a dosing regimen and therapeutic proposal. Front Pediatr 2019; 7: 188. doi: 10.3389/ fped.2019.00188. eCollection 2019.

56.- Allegaert K, Flint R, Smits A. Pharmacokinetic modelling and Bayesian estimation-assisted decision tools to optimize vancomycin dosage in neonates: only one piece of the puzzle. Expert Opin Drug Metab Toxicol 2019; 15(9): 735-49. doi: 10.1080/17425255.2019.1655540. Epub 2019 Aug 19.

57.- Germovsek E, Osborne L, Gunaratnam F, Lounis SA, Busquets FB, Standing JF, et al. Development and external evaluation of a population pharmacokinetic model for continuous and intermittent administration of vancomycin in neonates and infants using prospectively collected data. J Antimicrob Chemother 2019; 74(4): 1003-11. doi: 10.1093/ jac/dky525.

58.- Gwee A, Cranswick N, McMullan B, Perkins E, Bolisetty S, Gardiner K, et al. Continuous versus intermittent vancomycin infusions in infants: a randomized controlled trial. Pediatrics 2019; 143 (2): e20182179. doi: 10.1542/ peds.2018-2179.

59.- Plan O, Cambonie G, Barbotte E, Meyer P, Devine C, Milesi C, et al. Continuous-infusion vancomycin therapy for preterm neonates with suspected or documented Gram-positive infections: a new dosage schedule Arch Dis Child Fetal Neonatal Ed. 2008; 93 (6): F41821. doi: 10.1136/adc. 2007.

60.- Cristea S, Allegaert K, Falcao A C, Falcao F, Silva R, Smits A, et al. Larger dose reductions of vancomycin required in neonates with patent ductus arteriosus receiving indomethacin versus ibuprofen. Antimicrob Agents Chemother 2019; 63 (8): e00853-19. doi: 10.1128/AAC.0085319. Print 2019 Aug.

61.- Autmizguine J, Melloni C, Hornik C P, Dallefeld S, Harper B, Yogev R, et al. Population pharmacokinetics of trimethoprimsulfamethoxazole in infants and children. Antimicrob Agents Chemother 2017; 62(1). pii: e01813-17. doi: 10.1128/AAC.01813-17. Print 2018 Jan.

62.- Springer C, Eyal F, Michel J. Pharmacology of trimethoprim-sulfamethoxazole in newborn infants. J Pediatr 1982; 100 (4): 647-50. doi: 10.1016/s0022-3476(82)80778-6.

63.- Ryan K L, Dersch-Mills D, Clark D. Trimethoprim-sulfamethoxazole for treatment of Stenotrophomonas maltophilia pneumonia 
in a neonate. Can J Hosp Pharm 2013; 66 (6):

384-7. doi: 10.4212/cjhp.v66i6.1305.

64.- Thyagarajan B, Deshpande S S. Cotrimoxazole and neonatal kernicterus: a review. Drug Chem Toxicol 2014; 37(2): 121-9. doi: 10.3109/01480545.2013.834349. Epub 2013 Oct 7.

65.- Merchan L M, Hassan H E, Terrin M L, Waites K B, Kaufman D A, Ambalavanan N, et al. Pharmacokinetics, microbial response, and pulmonary outcomes of multidose intravenous azithromycin in preterm infants at risk for Ureaplasma respiratory colonization. Antimicrob Agents Chemother 2015; 59 (1): 570-8. doi: 10.1128/AAC.03951-14. Epub 2014 Nov 10.

66.- Viscardi R M, Othman A A, Hassan H E, Eddington N D, Abebe E, Terrin M L, et al. Azithromycin to prevent bronchopulmonary dysplasia in Ureaplasma infected preterm infants: pharmacokinetics, safety, microbial response and clinical outcomes with a 20-milligram-per-kilogram single intravenous dose. Antimicrob Agents Chemother 2013; 57 (5): 2127-33. doi: 10.1128/AAC.02183-12. Epub 2013 Feb 25.

67.- West S K, Moncada J, Munoz B, Mkocha H, Storey P, Hardick J, et al. Is there evidence for resistance of ocular Chlamydia trachomatis to azithromycin after mass treatment for trachoma control? J Infect Dis 2014; 210 (1): 65-71. doi: 10.1093/infdis/jiu046. Epub 2014 Jan 19.

68.- Eberly MD, Eide MB, Thompson JL, Nylund CM. Azithromycin in early infancy and pyloric stenosis. Pediatrics 2015; 135(3): 483-8. doi: 10.1542/peds.2014-2026.

69. Viscardi R M, Terrin M L, Magder L S, Davis N L, Dulkerian S J, Waites K B, et al. Randomised trial of azithromycin to eradicate Ureaplasma in preterm infants. Arch Dis Child Fetal Neonatal Ed. 2020; fetal neonatal-2019-318122. doi: 10.1136/ archdischild-2019-318122. Online ahead of print.

70.- Pinto L A, Pitrez P M, Luisi F, de Mello P P, Gerhardt M, Ferlini R, et al. Azithromycin therapy in hospitalized infants with acute bronchiolitis is not associated with better clinical outcomes: a randomized, doubleblinded, and placebo-controlled clinical trial. J Pediatr 2012; 161(6): 1104-8. doi: 10.1016/j. jpeds.2012.05.053.

71.- Cramer C L, Patterson A, Alchakaki A, Soubani A O. Immunomodulatory indications of azithromycin in respiratory disease: a concise review for the clinician. Postgrad Med 2017; 129(5): 493-9. doi: 10.1080/00325481.2017.1285677. Epub 2017 Feb 1

72.- Smith C, Egunsola O, Choonara I, Kotecha $\mathrm{S}$, Jacqz-Aigrain E, Sammons H. Use and safety of azithromycin in neonates. BMJ
Open 2015; 5 (12):e008194. doi: 10.1136/ bmjopen-2015-008194.

73.- Zikic A, Schünemann H, Wi T, Lincetto O, Broutet N, Santesso N. Treatment of neonatal chlamydial conjunctivitis: a systematic review and meta-analysis. J Pediatric Infect Dis Soc. 2018; 7 (3): e107-e115. doi: 10.1093/jpids/ piy060.

74.- Sicard M, Moussa A, Barrington K, Martin B, Luu T M, Ting J Y, et al. Neonatal and neurodevelopmental outcomes following linezolid for coagulase-negative staphylococcal infection: real world evidence. Pediatr Infect Dis J. 2020 Feb 20-07-01. doi: 10.1097/ INF.0000000000002619. Online ahead of print.

75.- Kearns G L, Jungbluth G L, Abdel-Rahman S M, Hopkins N K, Welshman I R, Grzebyk $\mathrm{R} P$, et al. Impact of ontogeny on linezolid disposition in neonates and infants. Clin Pharmacol Ther 2003; 74(5): 413-22. doi: 10.1016/S0009-9236(03)00226-1.

76.- Luque S, Grau S, Alvarez-Lerma F, Ferrández O, Campillo N, Horcajada J P, et al. Plasma and cerebrospinal fluid concentrations of linezolid in neurosurgical critically ill patients with proven or suspected central nervous system infections. Int J Antimicrob Agents 2014; 44(5): 409-15. doi: 10.1016/j.ijantimicag.2014.07.001

77.- Sicard M, Launay E, Caillon J, Jacqueline C, Legrand A, Deslandes G, et al. Pharmacokinetics of linezolid treatment using intravenous and oral administrations in extremely premature infants. Eur J Clin Pharmacol 2015; 71(5): 611-5. doi: 10.1007/ s00228-015-1813-3.

78.- Thibault C, Kassir N, Goyer I, Théorêt Y, Litalien C, Moussa A, et al. Population pharmacokinetics of intravenous linezolid in premature infants. Pediatr Infect Dis J 2019; 38(1): 82-8. doi: 10.1097/ INF.0000000000002067.

79.- Shibata Y, Hagihara M, Kato H, Asai N, Koizumi Y, Watarai M, et al. Relationship between cytopenia and gestational age in infants and neonates treated with linezolid therapy. J Infect Chemother 2020; 26(1): 95 100. doi: 10.1016/j.jiac.2019.07.022.

80.- Michalopoulos A S, Karatza D C. Multidrugresistant Gram-negative infections: the use of colistin. Expert Rev Anti Infect Ther 2010; 8: 1009-17. doi: 10.1586/eri.10.88.

81.- Kapoor K, Jajoo M, Dublish S, Dabas V, Gupta S, Manchada V. Intravenous colistin for multidrug-resistant Gram-negative infections in critically ill pediatric patients. Pediatr Crit Care Med 2013; 14(6):e268-72. doi: 10.1097/ PCC.0b013e31828a740f.

82.- Iosifidis E, Antachopoulos C, Ioannidou M, Mitroudi M, Sdougka M, Drossou-Agakidou $\mathrm{V}$, et al. Colistin administration to pediatric and neonatal patients. Eur J Pediatr 2010; 169 (7): 867-74. doi: 10.1007/s00431-009-1137-3.
83.- Celebi S, Hacimustafaoglu M, Koksal N, Ozkan H, Cetinkaya M. Colistimethate sodium therapy for multidrug-resistant isolates in pediatric patients. Pediatr Int 2010; 52: 410-4. doi: 10.1111/j.1442-200X.2009.03015.x.

84.- Jajoo M, Kumar V, Jain M, Kumari $\mathrm{S}$, Manchanda V. Intravenous colistin administration in neonates. Pediatr Infect Dis J 2011; 30: 218-21. doi: 10.1097/ INF.0b013e3182064bfe.

85.- Çağan E, Kıray Baş E, Asker HS. Use of colistin in a neonatal intensive care unit: a cohort study of 65 patients. Med Sci Monit 2017; 23: 548-54. doi: 10.12659/MSM.898213.

86.- Pogue J M, Lee J, Marchaim D, Yee V, Zhao J $\mathrm{J}$, Chopra T, et al. Incidence of and risk factors for colistin-associated nephrotoxicity in a large academic health system. Clin Infect Dis 2011; 53(9): 879-84. doi: 10.1093/cid/cir611.

87.- Yahav D, Farbman L, Leibovici L, Paul M. Colistin: New lessons on an old antibiotic. Clin Microbiol Infect 2012; 18(1): 18-29. doi: 10.1111/j.1469-0691.2011.03734.x.

88.- Karli A, Paksu M S, Karadag A, Belet N, Paksu S, Guney A K, et al. Colistin use in pediatric intensive care unit for severe nosocomial infections: experience of an university hospital. Ann Clin Microbiol Antimicrob 2013; 12: 32. doi: 10.1186/1476-0711-12-32.

89.- Shahbazi F, Dashti-Khavidaki S. Colistin: efficacy and safety in different populations. Expert Rev Clin Pharmacol 2015; 8(4): 423-48. doi: 10.1586/17512433.2015.1053390. Epub 2015 Jun 3.

90.- İpek M S, Aktar F, Okur N, Celik M, Ozbek E. Colistin use in critically ill neonates: A casecontrol study, Pediatr Neonatol 2017; 58(6): 490-6, doi: 10.1016/j.pedneo.2016.10.002.

91.- Couet W, Grégoire N, Gobin P, Saulnier P J, Frasca D, Marchand S, et al. Pharmacokinetics of colistin and colistimethate sodium after a single $80-\mathrm{mg}$ intravenous dose of CMS in young healthy volunteers. Clin Pharmacol Ther 2011; 89: 875-9. doi: 10.1038/clpt.2011.48.

92.- Nakwan N, Chokephaibulkit K, Imberti $\mathrm{R}$. The use of colistin for the treatment of multidrug-resistant gram-negative infections in neonates and infants: a review of the literature. Pediatr Infect Dis J 2019; 38(11): 1107-12. doi: 10.1097/INF.0000000000002448.

93.- Zhao W, Hill H, Le Guellec C, Neal T, Mahoney S, Paulus S, et al; TINN Consortium. Population pharmacokinetics of ciprofloxacin in neonates and young infants less than three months of age. Antimicrob Agents Chemother 2014; 58(11): 6572-80. doi: 10.1128/ AAC.03568-14. Epub 2014 Aug 25.

94.- Kaguelidou F, Turner M A, Choonara I, JacqzAigrain E. Ciprofloxacin use in neonates: a systematic review of the literature. Pediatr Infect Dis J 2011; 30(2):e29-37. doi: 10.1097/ INF.0b013e3181fe353d. 